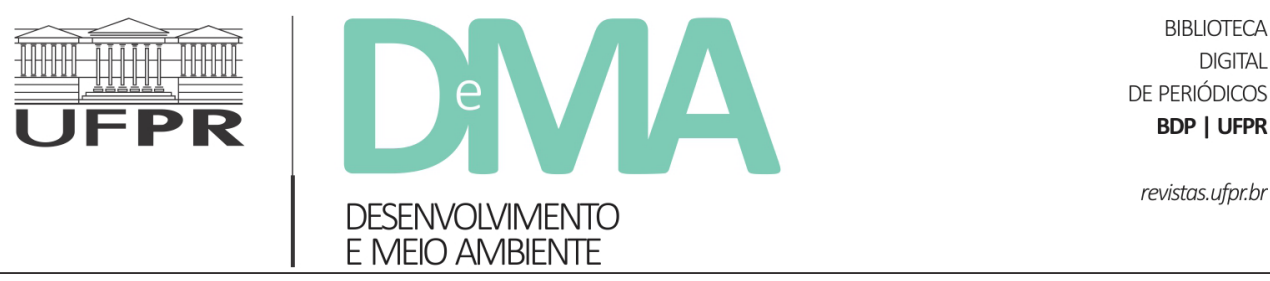

\title{
Agrotóxicos: críticas à regulação que permite o envenenamento do país
}

\section{Pesticides: criticisms of the regulation that allows poisoning the country}

\author{
Sonia Corina HESS ${ }^{1 *}$, Rubens Onofre NODARI ${ }^{2}$, Monica LOPES-FERREIRA ${ }^{3}$ \\ ${ }^{1}$ Universidade Federal de Santa Catarina (UFSC) - Campus Curitibanos, Curitibanos, SC, Brasil. \\ ${ }^{2}$ Centro de Ciências Agrárias, Universidade Federal de Santa Catarina (UFSC), Florianópolis, SC, Brasil. \\ ${ }^{3}$ Laboratório de Toxicologia Aplicada, Instituto Butantan, São Paulo, SP, Brasil. \\ *E-mail de contato: soniahess@gmail.com
}

Artigo recebido em 30 de agosto de 2020, versão final aceita em 18 de fevereiro de 2021, publicado em 30 de junho de 2021.

\begin{abstract}
RESUMO: $\quad$ O artigo contém uma análise das autorizações para a comercialização e o consumo de agrotóxicos no país na última década, bem como os seus efeitos na saúde humana e no meio ambiente. No período entre $2010 \mathrm{e}$ 2018, a quantidade de agrotóxicos comercializados no Brasil aumentou mais do que o dobro do que cresceu a área cultivada no país. A permissividade da gestão de agrotóxicos no Brasil é ilustrada pelo fato de que, do total de ingredientes ativos químicos com registro no país em julho de 2020, 121 (30\%) não tinham uso permitido na União Europeia (EU). A razão da proibição do uso na EU dos produtos autorizados no Brasil, no período referido, está associada aos efeitos adversos a humanos e a outros organismos resultantes da exposição aos ingredientes químicos de agrotóxicos, já descritos na literatura científica. Soja, milho, algodão e cana-de-açúcar constam entre as culturas que tiveram o maior número de novos agrotóxicos com uso autorizado no Brasil entre janeiro de 2019 e junho de 2020. Outra falta de rigor na gestão de agrotóxicos é ilustrada pela deriva, que causa danos agudos e crônicos a terceiros. Adicionalmente, a fragilidade da norma brasileira refere-se ao estabelecimento de um valor de dose, abaixo da qual eles seriam seguros. Contudo, resultados experimentais de estudos mostraram, por exemplo, que os agrotóxicos à base de glifosato, melation e piriproxifem causaram a morte de embriões de peixes em apenas 24 horas de exposição, independentemente da concentração utilizada, desafiando assim a hipótese de que existe dose segura para a exposição a tais produtos. Dessa forma, é urgente não só aumentar o rigor científico dos estudos sobre o tema, mas também promover a participação pública nas tomadas de decisão, garantindo o acesso a todas as informações contidas nos dossiês que acompanham as solicitações de registro e de autorização dos agrotóxicos.
\end{abstract}

Palavras-chave: consumo de agrotóxicos; agravos à saúde; deriva; pulverização aérea; dose independente. 
ABSTRACT: The article contains an analysis of the marketing authorizations and the consumption of pesticides in the last decade, as well as their effects on human health and the environment. In the period between 2010 and 2018, the amount of pesticides sold in Brazil increased more than twice as much as the cultivated area in the country. The permissiveness of pesticide governance in Brazil is illustrated by the fact that, of the total chemical active ingredients with register in the country in July 2020, $121(30.0 \%)$ had no use allowed in the European Union (EU). The reason for the ban on the use in the EU of products authorized in Brazil, in the referred period, is associated with the adverse effects on humans and other organisms resulting from exposure to chemical ingredients of pesticides, already described in the scientific literature. Soybean, corn, cotton and sugar cane are among those that had the largest number of new pesticides authorized for use in Brazil between January 2019 and June 2020. Another lack of rigor in pesticide governance is illustrated by the drift, which causes acute and chronic damage to third parties. Another weakness of the Brazilian standard refers to the establishment of a dose value, below which, they would be safe. However, experimental results from studies have shown, for example, that pesticides based on glyphosate, melation and pyriproxifem caused the death of fish embryos in just 24 hours of exposure, regardless of the concentration used, challenging the hypotheses that there is safe dose for exposure to such pesticides. Thus, it is urgent that there is a need not only to increase the scientific rigor of the studies on the subject, but also to promote the public participation in decisionmaking process ensuring the access to all information contained in the dossiers accompanying requests for registration and authorization.

Keywords: consumption of pesticides; health problems; drift; aerial spraying; independent dose.

\section{Introdução}

O termo "agrotóxico", que expressa a conotação negativa relacionada à toxicidade das formulações destes produtos e sua inerente finalidade, começou a ser mais comumente usado a partir da década de 1980. Anteriormente, predominava a expressão "defensivo agrícola", sugerindo uma representação supostamente positiva ou neutra dos mesmos. Hoje em dia, ela continua sendo largamente utilizada, principalmente pelos agentes que respondem pela sua produção e inserção nos mercados concorrenciais globalizados (Carvalho et al., 2017).

Assim, a definição legalmente aceita hoje em dia leva em conta sobretudo o interesse comercial e não as externalidades negativas desses produtos. Na Lei n ${ }^{0} 7.802$, de 1989 (Brasil, 1989) e no decreto regulamentador $n^{\circ} 98.816$, datado de 1990 , agrotóxicos e afins são caracterizados como produtos e agentes de processos físicos, químicos ou biológicos que visam alterar a composição da flora ou da fauna a fim de preservá-las da ação de seres vivos considerados nocivos. Mas esta caracterização não guarda sintonia com as evidências científicas, as quais sinalizam que a ação adversa dos agrotóxicos independe da nocividade dos organismos-alvo que atingem. Anteriormente à aprovação da referida lei, $85 \%$ dos agrotóxicos eram enquadrados nas classes toxicológicas I e II. Após sua implementação, 6\% dos mesmos passaram a ser enquadrados nas classes toxicológicas I e II, as mais perigosas, e $94 \%$ nas classes III e IV, consideradas menos perigosas (Carvalho et al., 2017).

A Lei $n^{0} 7.802$ também definiu critérios para o não registro de certos tipos de agrotóxicos. No parágrafo $6^{\circ}$ do Artigo $3^{\circ}$ estão mencionadas as características que levam à proibição de substâncias teratogênicas, carcinogênicas ou mutagênicas; e daquelas capazes de provocar distúrbios hormonais, danos ao sistema reprodutor ou danos ao meio am- 
biente, de acordo com procedimentos e experiências consensuadas na comunidade científica. Dessa forma, compreender melhor e mais objetivamente os múltiplos riscos envolvidos na utilização de agrotóxicos constitui o primeiro passo na busca de formas de produção de alimentos mais saudáveis e com menor impacto ambiental e na saúde dos agricultores e consumidores (Carvalho et al., 2017).

Com base no exposto, o presente artigo oferece uma análise das autorizações de comercialização e consumo aprovadas na última década, tendo como base o Artigo $3^{\circ}$ da lei de Agrotóxicos. Este estudo decorre das evidências indicando não só que as autorizações têm sido cada vez mais frequentes, mas também que a lista de produtos formulados com ingredientes ativos proibidos em outros países estaria aumentado.

Para comprovar estas premissas, na primeira fase do estudo foram feitas consultas às fontes primárias das agências integrantes do Conselho Técnico de Agrotóxicos (CTA), Instituto Brasileiro do Meio Ambiente - IBAMA, Agência de Vigilância Sanitária (ANVISA), Ministério da Agricultura, Pecuária e Abastecimento (MAPA), que gerencia o sistema de Agrotóxicos Fitossanitário (AGROFIT). Na sequência, foram consultadas as fontes do Instituto Brasileiro de Geografia e Estatística (IBGE) e documentos de indústrias e de bancos relacionados ao tema. A base de dados sobre agrotóxicos da União Europeia também foi utilizada. Finalmente, efetivamos uma revisão da literatura cientifica centrada nos efeitos considerados mais danosos dos agrotóxicos mais utilizados no País, mobilizando para tanto as bases de dados Scielo, Portal de Periódicos Capes, Pubmed e Academia. Todavia, somente uma parte dos artigos foram utili- zados na elaboração do presente trabalho, em razão do volume excessivo de publicações catalogadas.

Mais precisamente, além da sistematização das autorizações de comercialização e consumo de agrotóxicos, o presente estudo colocou em foco os seus principais impactos sobre a saúde e o meio ambiente. Por se tratar de um tópico muito polêmico, o tema da deriva dos produtos aplicados está inserido numa seção especial. Procuramos mostrar de que maneira os efeitos esperados em determinados contextos podem se estender de forma imprevisível a outros, amplificando assim o potencial destrutivo dos agrotóxicos.

A partir da análise das fontes primárias, o artigo destaca também a especificidade do período que se estende de 2019 a junho de 2020 , no qual os índices de aprovação de produtos proibidos ou com restrição de uso aumentaram consideravelmente em relação a outros períodos. Dentre os produtos, a importação daqueles banidos ou com restrições aumentou também mais do que a média verificada nesta década.

Conforme já mencionado, a sociedade espera que as decisões de registro, produção e importação sejam pautadas em procedimentos e experiências atualizadas na comunidade científica, já que há previsão legal para isso. Nos dados compilados, são compartilhados exemplos de agrotóxicos cuja autorização de importação e uso no País não estão sendo cumpridos à risca. Por outro lado, não abordamos as falhas no controle da qualidade da água para consumo humano (relacionadas à presença de resíduos de agrotóxicos) pelo fato de já terem sido objeto de um estudo anterior (Hess, 2018). 


\section{Ingredientes ativos de agrotóxicos com uso autorizado e quantidade consumida no Brasil na última década}

Os relatórios de comercialização de agrotóxicos divulgados pelo Instituto Brasileiro do Meio Ambiente - IBAMA (2020) revelam que entre 2010 e 2018 houve um aumento de $43 \%$ na quantidade de agrotóxicos comercializados no Brasil. Foram 384.501,28 toneladas vendidas em 2010 e 549.280,44 em 2018. Por outro lado, naquele mesmo período de 2010 a 2018, a soma das áreas cultivadas para as culturas temporárias e permanentes aferidas pelo IBGE (2020) indica incremento de apenas $20 \%$ (65.374.591 hectares cultivados em 2010 e 78.502 .422 hectares em 2018). Desta maneira, a quantidade de agrotóxicos comercializados no Brasil aumentou mais do que o dobro do que cresceu a área cultivada no país, entre 2010 e 2018.

Em julho de 2020, na lista das monografias autorizadas, constavam 455 ingredientes ativos de agrotóxicos para uso agrícola e/ou domissanitário no Brasil, sendo 404 químicos $(88,8 \%)$ e 51 biológicos (11,2\%) (ANVISA, 2020). Dentre esses 404 ingredientes ativos químicos, pelo menos 121 $(30,0 \%)$ não tinham uso permitido na União Europeia (European Comission, 2020b) (Tabela 1).

Nos boletins anuais de produção, importação, exportação e vendas de agrotóxicos no Brasil, para o ano de 2018 (IBAMA, 2020), constam dados de apenas 88 dos 404 ingredientes ativos químicos com uso permitido em produtos comerciais no país
(21,8\% do total). A explicação para a omissão das quantidades anuais comercializadas dos demais $78,2 \%$ ingredientes ativos consta no portal do IBAMA na internet: "serão divulgados apenas os dados dos ingredientes ativos que possuam no mínimo 3 empresas detentoras do registro, preservando assim o sigilo comercial"'. Como resultado da aplicação desse critério, não constam nesses boletins, por exemplo, dados relativos ao neonicotinóide tiametoxam - banido na União Europeia em 2009 (European Comission, 2020b) que, segundo Bain \& Company (2014), em 2012 foi o inseticida mais comprado pelo país, com importações que alcançaram 341 milhões de dólares - , nem do fungicida piraclostrobina, com importações estimadas em 278 milhões de dólares. Comparativamente, em 2012, as importações de herbicida à base de glifosato, o agrotóxico mais comercializado no Brasil, movimentaram 225 milhões de dólares (Bain \& Company, 2014).

Entre os 20 ingredientes ativos dos agrotóxicos de produtos comerciais mais vendidos no país em 2018 , dentre os 88 produtos da lista divulgada pelo IBAMA (2020), nove deles constam como uso não autorizado na União Europeia: acefato (o $5^{\circ}$ mais vendido), ametrina $\left(17^{\circ}\right)$, atrazina $\left(4^{\circ}\right)$, carbendazim $\left(15^{\circ}\right)$, clorotalonil $\left(12^{\circ}\right)$, clorpirifós $\left(13^{\circ}\right)$, metomil $\left(18^{\circ}\right)$, tebutiurom $\left(19^{\circ}\right)$ e tiofanato-metílico $\left(20^{\circ}\right)$, que totalizaram 97.816,3 toneladas de ingredientes ativos comercializadas em 2018 (European Comission, 2020b; IBAMA, 2020) (Tabela 1).

\footnotetext{
${ }^{1}$ Instituto Brasileiro do Meio Ambiente. Relatórios de comercialização de agrotóxicos. Disponível em: <http://www.ibama.gov.br/agrotoxicos/ relatorios-de-comercializacao-de-agrotoxicos\#boletinsanuais>.
} 
TABELA 1 - Ingredientes ativos químicos de agrotóxicos com uso autorizado no Brasil em julho de 2020, ano de proibição do uso na EU, classe de uso, quantidade comercializada em 2018 e número de produtos comerciais registrados para cada ingrediente ativo.

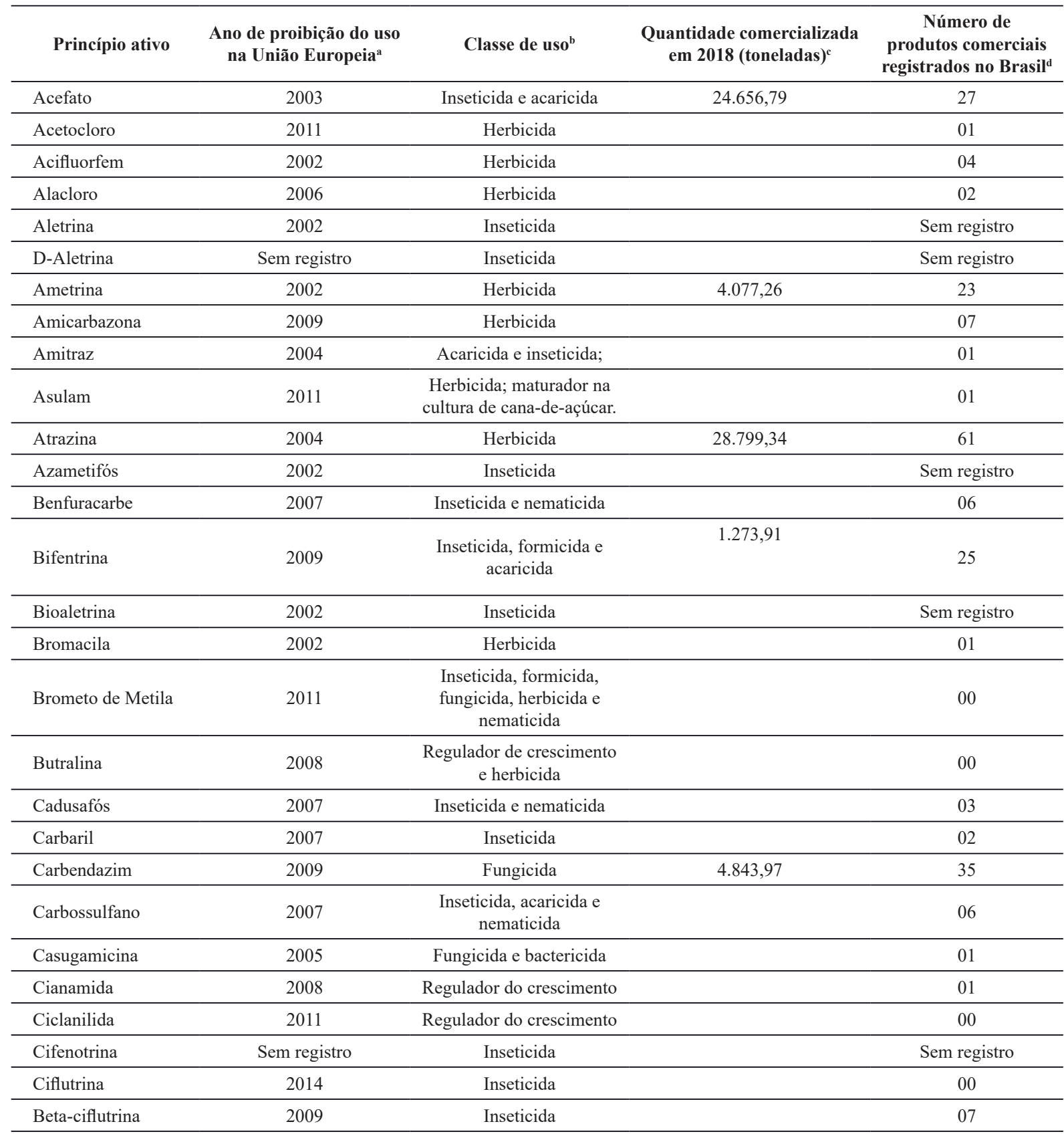




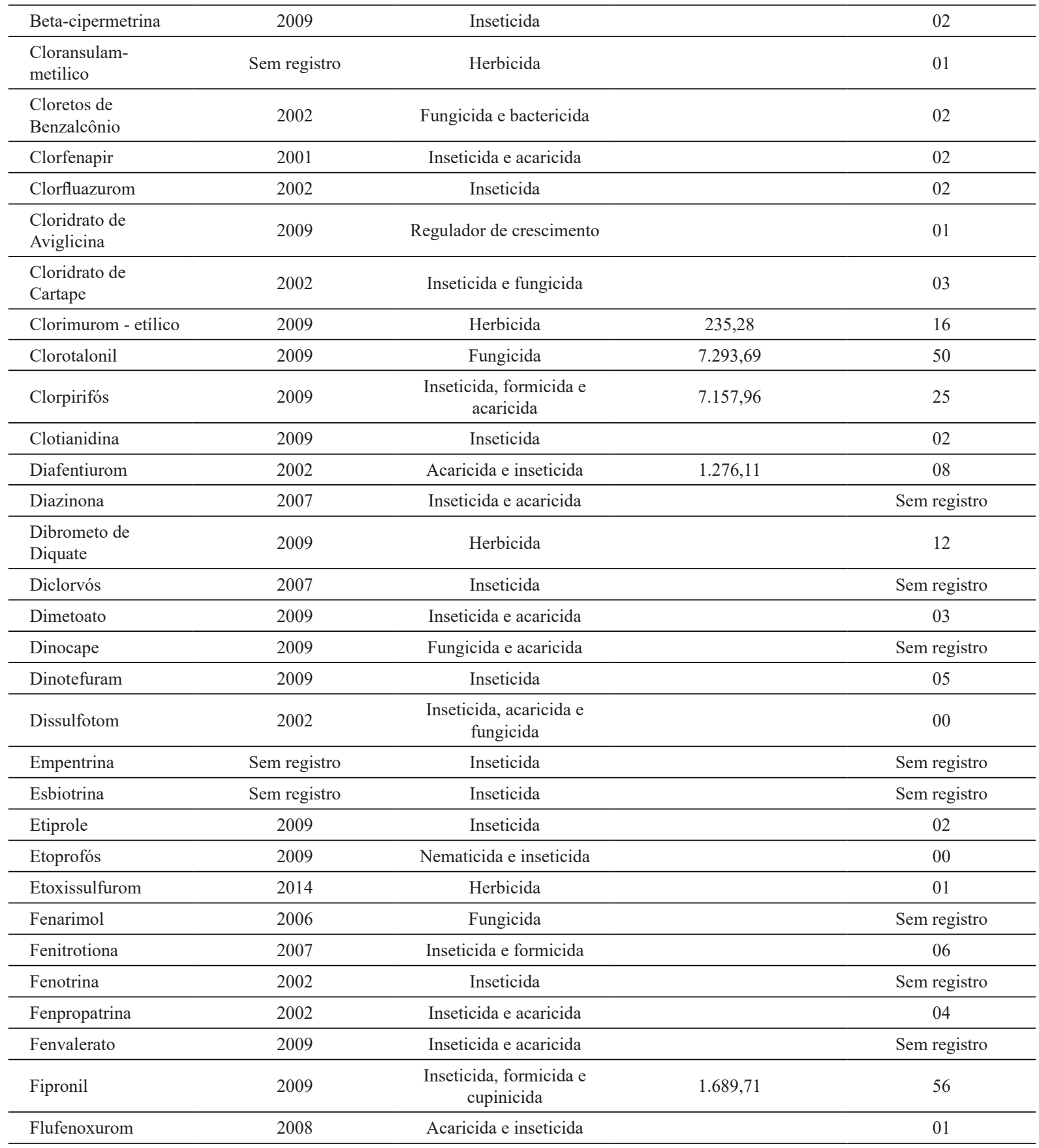




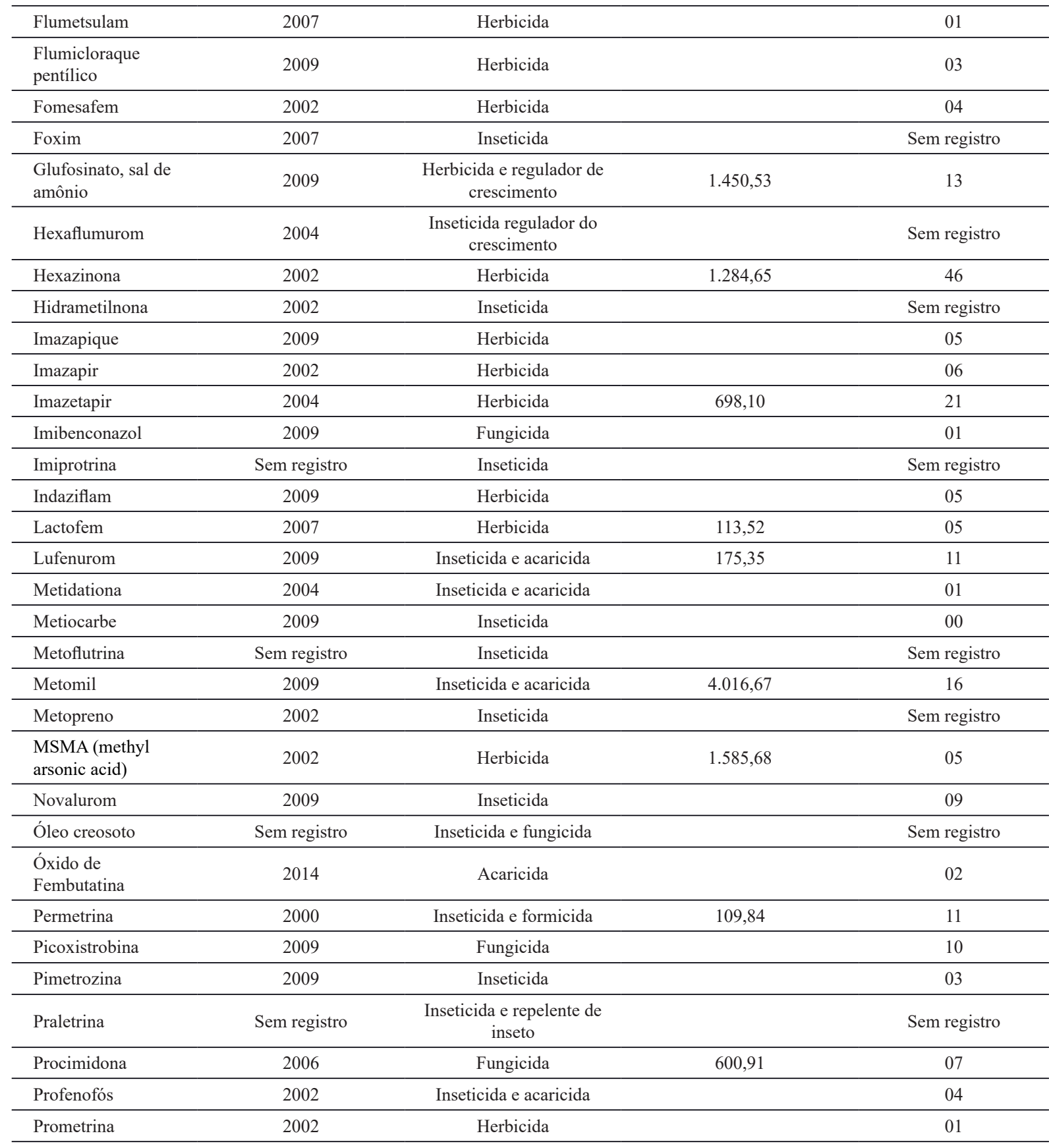




\begin{tabular}{|c|c|c|c|c|}
\hline Propanil & 2019 & Herbicida & 241,30 & 10 \\
\hline Propargito & 2008 & Acaricida & 306,81 & 06 \\
\hline Propiconazol & 2009 & Fungicida & 795,05 & 11 \\
\hline Propoxur & 2002 & Inseticida & & Sem registro \\
\hline Quintozeno & 2000 & Fungicida & & 01 \\
\hline Serricornim & 2004 & Feromônio sintético & & 04 \\
\hline Setoxidim & 2002 & Herbicida & & 02 \\
\hline Simazina & 2004 & Herbicida & 351,45 & 14 \\
\hline Sulfentrazona & 2009 & Herbicida & $1.564,48$ & 14 \\
\hline Sulfluramida & Sem registro & Inseticida e formicida & & 09 \\
\hline Sumitrina & 2009 & Inseticida & & Sem registro \\
\hline Tebupirinfós & Sem registro & Inseticida & & 01 \\
\hline Tebutiurom & 2002 & Herbicida & $3.770,64$ & 22 \\
\hline Teflubenzurom & 2009 & Inseticida & & 04 \\
\hline Temefós & 2002 & Inseticida, larvicida & & Sem registro \\
\hline Terbufós & 2002 & Inseticida e nematicida & & 01 \\
\hline Tetradifona & 2002 & Acaricida & & 00 \\
\hline Tetrametrina & 2002 & Inseticida & & Sem registro \\
\hline D-Tetrametrina & Sem registro & Inseticida & & Sem registro \\
\hline Tiacloprido & 2009 & Inseticida & & 01 \\
\hline Tiametoxam & 2009 & Inseticida & & 22 \\
\hline Tiazopir & 2002 & Herbicida & & 01 \\
\hline Tidiazurom & 2008 & $\begin{array}{l}\text { Herbicida e regulador de } \\
\text { crescimento }\end{array}$ & & 04 \\
\hline Tiodicarbe & 2007 & Inseticida & $1.627,79$ & 23 \\
\hline Transflutrina & Sem registro & Inseticida & & Sem registro \\
\hline Triadimefom & 2004 & Fungicida & & Sem registro \\
\hline Triazafós & 2002 & $\begin{array}{c}\text { Inseticida, acaricida e } \\
\text { nematicida }\end{array}$ & & 00 \\
\hline Trifluralina & 2010 & Herbicida & $2.329,61$ & 08 \\
\hline Trimedlure & 2004 & Feromônio sintético & & 02 \\
\hline
\end{tabular}

FONTE: Organizado pelos autores a partir de ${ }^{a}$ European Comission (2020b); ${ }^{b}$ ANVISA (2020); ${ }^{\mathrm{C} I B A M A, ~(2020) ; ~}{ }^{\mathrm{d} S i s t e m a}$ AGROFIT do Ministério da Agricultura, Pecuária e Abastecimento (2020). 
Dos 768 produtos comerciais que contêm ingredientes ativos de agrotóxicos registrados no sistema AGROFIT do Ministério da Agricultura, Pecuária e Abastecimento (2020) e com uso proibido na União Europeia, os cinco ingredientes ativos presentes em maior número são: atrazina (61 produtos), fipronil (56), clorotalonil (50), hexazinona (46) e carbendazim (35). Por outro lado, dentre os 121 ingredientes ativos sem uso autorizado na União Europeia e permitidos no Brasil, vinte e nove $(24,0 \%)$ não estavam registrados no sistema AGROFIT e nove $(7,4 \%)$ não tinham produtos comerciais registrados no sistema (Ministério da Agricultura, Pecuária e Abastecimento, 2020) (Tabela 1).

\section{Produtos comerciais contendo agrotóxicos que tiveram uso autorizado no Brasil entre janeiro de 2019 e junho de 2020}

Com relação aos novos produtos contendo agrotóxicos com uso autorizado no Brasil no período compreendido entre 09 de janeiro de 2019 e 05 de junho de 2020, os dados descritos nos atos da Coordenação Geral de Agrotóxicos e Afins do Departamento de Sanidade Vegetal e Insumos Agrícolas da Secretaria de Defesa Agropecuária do Ministério da Agricultura, Pecuária e Abastecimento(Brasil, 2020) revelam que: a) dos 680 novos produtos aprovados (503 em 2019, 177 em 2020), 69 contêm agentes biológicos de controle de pragas $(10,1 \%)$ e $611(89,9 \%)$ são produtos contendo ingredientes ativos químicos; b) entre os produtos contendo agentes biológicos de controle de pragas agrícolas, 65 (94,2\%) têm fabricantes com sede no Brasil; c) por outro lado, dentre os fabricantes dos agrotóxicos com ingredientes ativos químicos, $63,2 \%$ têm sede na China, 9,8\% na Índia e apenas 2,7\% têm sede no Brasil; d) em ordem decrescente, os agrotóxicos químicos com uso autorizado no Brasil entre janeiro de 2019 e junho de 2020 estão incluídos nas seguintes classes de uso: herbicida e/ ou regulador de crescimento e/ou ativador de planta (310 produtos, 50 ingredientes ativos); inseticida e/ou nematicida e/ou formicida e/ou cupinicida e/ ou acaricida e/ou moluscicida (219 produtos, 34 ingredientes ativos); e fungicida e/ou bactericida (170 produtos, 31 ingredientes ativos) (Tabela 2); e) entre os 611 produtos contendo ingredientes químicos de agrotóxicos aprovados para uso no Brasil entre janeiro de 2019 e junho de 2020, 252 $(41,2 \%)$ contêm ingredientes ativos de agrotóxicos proibidos na União Europeia.

O herbicida e regulador de crescimento glufosinato de amônio, banido na UE em 2009, foi o ingrediente ativo presente no maior número de agrotóxicos aprovados (40). No total, dentre os 113 ingredientes ativos químicos presentes nos produtos aprovados, 37 (32,7\%) não têm uso aprovado na União Europeia (Tabela 2). A proibição desses produtos na UE está associada aos efeitos adversos a humanos e a outros organismos resultantes da exposição aos ingredientes químicos de agrotóxicos, já descritos na literatura científica e sumarizados na Tabela 3. 
TABELA 2 - Número de produtos comerciais, classe de uso e ano de proibição na União Europeia de ingredientes ativos de agrotóxicos que tiveram uso autorizado no Brasil entre janeiro de 2019 e junho de 2020.

\begin{tabular}{|c|c|c|c|}
\hline Ingrediente ativo & $\begin{array}{l}\text { Número produtos comerciais } \\
\text { aprovados no período }\end{array}$ & $\begin{array}{l}\text { Ano de proibição do uso na } \\
\text { União Europeia }^{\text {b }}\end{array}$ & Classe de uso ${ }^{c}$ \\
\hline $2,4-\mathrm{D}$ e seus sais & 24 & & Herbicida \\
\hline Acefato & 5 & 2003 & Inseticida e acaricida \\
\hline Acetamiprido & 10 & & Inseticida \\
\hline Ácido giberélico & 4 & & Regulador de crescimento \\
\hline Ácido 4-indol-3-ilbutírico & 2 & & Regulador de crescimento \\
\hline Ametrina & 9 & 2002 & Herbicida \\
\hline Amicarbazona & 1 & 2009 & Herbicida \\
\hline Benziladenina & 2 & & Regulador de crescimento \\
\hline Benzovindiflupir & 2 & & Fungicida \\
\hline Bifentrina & 5 & 2009 & Inseticida, formicida e acaricida \\
\hline Bispiribaque-sódico & 2 & & $\begin{array}{l}\text { Herbicida e regulador de } \\
\text { crescimento }\end{array}$ \\
\hline Buprofezina & 1 & & Inseticida e acaricida \\
\hline Captana & 2 & & Fungicida \\
\hline Carbendazim & 1 & 2009 & Fungicida \\
\hline Cinetina & 2 & & Regulador do crescimento \\
\hline Ciproconazol & 11 & & Fungicida \\
\hline Ciprodinil & 1 & & Fungicida \\
\hline Cletodim & 9 & & Herbicida \\
\hline Clomazona & 7 & & Herbicida \\
\hline Cloransulam-metilico & 1 & $\begin{array}{l}\text { Sem registro na União } \\
\text { Europeia }^{\mathbf{b}}\end{array}$ & Herbicida \\
\hline Cloreto de Mepiquate & 1 & & Regulador do crescimento \\
\hline Clorfenapir & 8 & 2001 & Inseticida e acaricida \\
\hline
\end{tabular}




\begin{tabular}{|c|c|c|c|}
\hline Cloridrato de Cartape & 1 & 2002 & Inseticida e fungicida \\
\hline Clorimurom-etílico & 4 & 2009 & Herbicida \\
\hline Clorotalonil & 14 & 2009 & Fungicida \\
\hline Clorpirifós & 15 & 2009 & Inseticida, formicida e acaricida \\
\hline Cresoxim-metílico & 1 & & Fungicida \\
\hline Deltametrina & 2 & & Inseticida e formicida \\
\hline Diafentiurom & 6 & 2002 & Acaricida e inseticida \\
\hline Dibrometo de Diquate & 3 & 2009 & Herbicida \\
\hline Dicamba & 4 & & Herbicida \\
\hline Difenoconazol & 18 & & Fungicida \\
\hline Diflubenzurom & 3 & & Inseticida e acaricida \\
\hline Dinotefuram & 6 & 2009 & Inseticida \\
\hline Diurom & 6 & & Herbicida \\
\hline Espirodiclofeno & 3 & & Acaricida \\
\hline Fipronil & 19 & 2009 & Inseticida, formicida e cupinicida \\
\hline Florpirauxifen-benzil & 3 & & Herbicida \\
\hline Fluazinam & 8 & & Fungicida e acaricida \\
\hline Flubendiamida & 1 & & Inseticida \\
\hline Fludioxonil & 4 & & Fungicida \\
\hline Fluopiram & 4 & & Fungicida \\
\hline Fluroxipir-metilico & 7 & & Herbicida \\
\hline Flutolanil & 1 & & Fungicida \\
\hline Flutriafol & 6 & & Fungicida \\
\hline Fluxapiroxade & 5 & & Fungicida \\
\hline Folpete & 1 & & Fungicida \\
\hline Fomesafem & 5 & 2002 & Herbicida \\
\hline Fosetil & 1 & & Fungicida \\
\hline Fosfato férrico & 1 & & Moluscicida \\
\hline Fosfina & 1 & & $\begin{array}{l}\text { Inseticida fumigante, formicida e } \\
\text { cupinicida }\end{array}$ \\
\hline Glifosato e seus sais & 19 & & Herbicida \\
\hline Glufosinato, Sal de Amônio. & 40 & 2009 & $\begin{array}{l}\text { Herbicida e regulador de } \\
\text { crescimento }\end{array}$ \\
\hline Haloxifope-P-metílico & 1 & & Herbicida \\
\hline Hexazinona & 11 & 2002 & Herbicida \\
\hline Imazalil & 1 & & Fungicida \\
\hline Imazapique & 4 & 2009 & Herbicida \\
\hline
\end{tabular}




\begin{tabular}{|c|c|c|c|}
\hline Imazapir & 4 & 2002 & Herbicida \\
\hline Imazetapir & 6 & 2004 & Herbicida \\
\hline Imidacloprido & 9 & & Inseticida \\
\hline Indaziflam & 2 & 2009 & Herbicida \\
\hline Indoxacarbe & 13 & & Inseticida, cupinicida e formicida \\
\hline Isoxaflutol & 10 & & Herbicida \\
\hline Lactofem & 1 & 2007 & Herbicida \\
\hline Lambda-cialotrina & 10 & & Inseticida \\
\hline Lufenurom & 6 & 2009 & Inseticida e acaricida \\
\hline Malationa & 5 & & Inseticida e acaricida \\
\hline Mancozebe & 13 & & Fungicida e acaricida \\
\hline Mesotriona & 6 & & Herbicida \\
\hline Metalaxil-M & 2 & & Fungicida \\
\hline Metilciclopropeno & 3 & & Regulador de crescimento \\
\hline S-Metolacloro & 10 & & Herbicida \\
\hline Metomil & 6 & 2009 & Inseticida e acaricida \\
\hline Metoxifenozida & 7 & & Inseticida \\
\hline Metribuzim & 4 & & Herbicida \\
\hline Metsulfurom-metílico & 1 & & Herbicida \\
\hline Nicossulfurom & 7 & & Herbicida \\
\hline Novalurom & 10 & 2009 & Inseticida \\
\hline Oxicloreto de Cobre & 5 & & Fungicida e bactericida \\
\hline Paclobutrazol & 4 & & Regulador de crescimento \\
\hline Pendimetalina & 1 & & Herbicida \\
\hline Penoxsulam & 1 & & Herbicida \\
\hline Permetrina & 1 & 2000 & Inseticida e formicida \\
\hline Picloram & 7 & & Herbicida \\
\hline Picoxistrobina & 4 & 2009 & Fungicida \\
\hline Piraclostrobina & 4 & & Fungicida \\
\hline Piriproxifem & 12 & & Inseticida \\
\hline Profenofós & 3 & 2002 & Inseticida e acaricida \\
\hline Propanil & 2 & 2019 & Herbicida \\
\hline Propiconazol & 1 & 2009 & Fungicida \\
\hline Protioconazol & 1 & & Fungicida \\
\hline Quizalofope-P-etílico & 2 & & Herbicida \\
\hline Simazina & 5 & 2004 & Herbicida \\
\hline Sulfentrazona & 12 & 2009 & Herbicida \\
\hline
\end{tabular}




\begin{tabular}{lccc}
\hline Sulfoxaflor & 11 & Inseticida & Fungicida \\
\hline Tebuconazol & 10 & 2002 & Herbicida \\
\hline Tebutiurom & 7 & 2009 & Fungicida \\
\hline Tiabendazol & 2 & 2007 & Inseticida \\
\hline Tiametoxam & 7 & Inseticida & Fungicida \\
\hline Tiodicarbe & 3 & Herbicida \\
\hline Tiofanato-metílico & 12 & Regulador de crescimento \\
\hline Triclopir-butotílico & 11 & & \\
\hline Trinexapaque-etilico & 8 & & \\
\hline
\end{tabular}

FONTE: organizado pelos autores a partir de ${ }^{a}$ Brasil (2020); ${ }^{b}$ European Comission (2020b); ${ }^{\mathrm{c} A N V I S A ~(2020) . ~}$

TABELA 3 - Efeitos resultantes da exposição a ingredientes químicos dos agrotóxicos com uso autorizado no Brasil entre janeiro de 2019 e junho de 2020 .

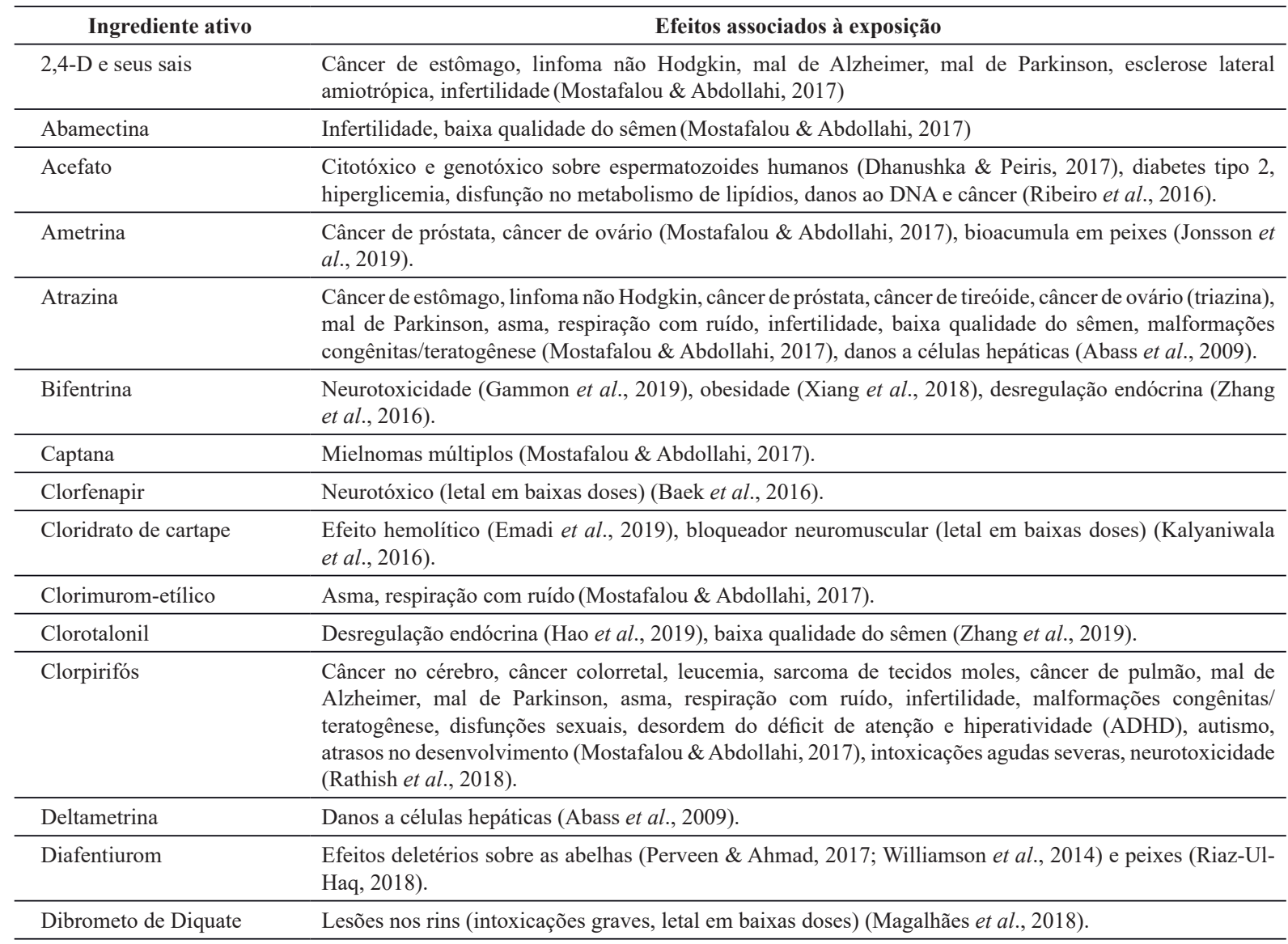




\begin{tabular}{|c|c|}
\hline Dinotefuram & $\begin{array}{l}\text { Resíduos persistentes na água e em organismos. Não atende ao limite máximo de resíduo, } 0,01 \mathrm{mg} / \mathrm{Kg}^{\mathrm{b}} \text {. } \\
\text { Efeitos deletérios sobre as abelhas (Williamson et al., 2014). }\end{array}$ \\
\hline Diurom & Bioacumula em peixes (Jonsson et al., 2019). \\
\hline Fipronil & $\begin{array}{l}\text { Alterações hematológicas e bioquímicas e stress oxidativo (Abouelghar et al., 2020), hepatotóxico e } \\
\text { neurotóxico (Gutta et al., 2019). }\end{array}$ \\
\hline Fluopiram & $\begin{array}{l}\text { Efeitos danosos ao crescimento de Vitis vinifera (uva) (Robatscher et al., 2019), efeitos deletérios sobre } \\
\text { nematoides não alvo (Waldo et al., 2019). }\end{array}$ \\
\hline Fomesafen & $\begin{array}{l}\text { Efeitos deletérios sobre as comunidades bacterianas da rizosfera (Hu et al., 2019) e minhocas (Zhang et } \\
\text { al., 2013). }\end{array}$ \\
\hline Glifosato e seus sais & $\begin{array}{l}\text { Linfoma não Hodgkin, infertilidade (Mostafalou \& Abdollahi, 2017), autismo (Von Ehrenstein, 2019), } \\
\text { problemas renais crônicos, danos às células embrionárias e da placenta, morte programada e necrose de } \\
\text { células placentárias, umbilicais e embrionárias, desregulador endócrino em células hepáticas, proliferação } \\
\text { de células de câncer de mama (Hess; Nodari, 2018), danos a células hepáticas (Abass et al., 2009). Em } \\
\text { abelhas aumenta a suceptibilidade a doenças (Faita et al., 2020), altera a membrana da mitocôndria e a } \\
\text { estrutura das células da glândula produtora de mel (Faita et al., 2018). }\end{array}$ \\
\hline Glufosinato, Sal de Amônio. & Genotoxicidade (Xiong et al., 2019), hepatotoxicidade, desregulação endócrina (Zhang et al., 2019). \\
\hline Hexazinona & $\begin{array}{l}\text { Resíduos persistentes na água e em organismos. Não atende ao limite máximo de resíduo, 0,01 mg/Kg } \\
\text { (European Comission, 2020b); bioacumula em peixes (Jonsson et al., 2019). }\end{array}$ \\
\hline Imazapique & Toxicidade aguda sobre peixes (Golombieski et al., 2016). \\
\hline Imazapir & Toxicidade aguda sobre peixes (Golombieski et al., 2016). \\
\hline Imazetapir & Câncer colorretal, câncer de bexiga (Mostafalou \& Abdollahi, 2017). \\
\hline Imidacloprido & $\begin{array}{l}\text { Desordem do déficit de atenção e hiperatividade (ADHD), autismo (Mostafalou \& Abdollahi, 2017), } \\
\text { efeitos deletérios sobre as abelhas (Perveen \& Ahmad, 2017; Williamson et al., 2014), genotóxico (Bianchi } \\
\text { et al., 2015, 2016). }\end{array}$ \\
\hline Lambda-cialotrina & Danos a células hepáticas (Abass et al., 2009). \\
\hline Lufenurom & $\begin{array}{l}\text { Efeitos tóxicos sobre organismos aquáticos (Brock et al., 2018); efeitos tóxicos severos, agudos e crônicos, } \\
\text { sobre peixe (tambaqui) (Soares et al., 2016); aumenta a suscetibilidade de minhocas a infecções (Wang et } \\
\text { al., 2013). }\end{array}$ \\
\hline Malationa & $\begin{array}{l}\text { Linfoma não Hodgkin, câncer de próstata, câncer de tireóide, desordem do déficit de atenção e hiperatividade } \\
\text { (ADHD), atrasos no desenvolvimento (Mostafalou \& Abdollahi, 2017), autismo (Von Ehrenstein, 2019) }\end{array}$ \\
\hline Mancozebe & Câncer de tireóide (Mostafalou \& Abdollahi, 2017). \\
\hline Metomil & $\begin{array}{l}\text { Mal de Alzheimer, mal de Parkinson (Mostafalou \& Abdollahi, 2017), efeitos neurotóxicos sobre peixes } \\
\text { (Yi et al., 2006). }\end{array}$ \\
\hline Novalurom & $\begin{array}{l}\text { Efeitos adversos sobre o bicho-da-seda (Santorum et al., 2019, 2020) e outros insetos não alvo (Stacke et } \\
\text { al., 2019). }\end{array}$ \\
\hline Permetrina & Autismo (Von Ehrenstein, 2019). \\
\hline Picoxistrobina & $\begin{array}{l}\text { Danos às mitocôndrias e à respiração celular (Xia et al., 2018), genotoxicidade (Li et al., 2018), efeitos } \\
\text { deletérios sobre as abelhas (Domingues et al., 2017). }\end{array}$ \\
\hline Piraclostrobina & Genotoxicidade (Li et al., 2018). \\
\hline Profenofós & $\begin{array}{l}\text { Agrotóxico organofosforado com sérios efeitos sobre a saúde, tanto por exposição aguda (problemas } \\
\text { urinários, bradicardia, coma, entre outros efeitos neurológicos, gastrointestinais, pulmonares e musculares) } \\
\text { quanto crônica (dores de cabeça, tremores, náusea, vômitos, dores abdominais, visão turva entre outros) } \\
\text { (Kushwaha et al., 2016; Nganchaumung et al., 2017), desregulador endócrino (Moustafa et al., 2008). }\end{array}$ \\
\hline
\end{tabular}




\begin{tabular}{ll}
\hline Propanil & Desregulador endócrino, efeitos deletérios sobre células do sistema imunológico (Nowak et al., 2019). \\
\hline Propiconazol & Efeitos danosos sobre células hepáticas humanas (Knebel et al., 2018, 2019) e de roedores (Nesnow et al., \\
& $\begin{array}{l}\text { 2011); induz câncer hepático em roedores e em peixe (Tu, 2016); danos ao cérebro e sobre o comportamento } \\
\text { de roedores (Noshy et al., 2018); danos ao cérebro do peixe zebra fish, causando também mudanças no seu } \\
\text { comportamento (Valadas et al., 2019). }\end{array}$ \\
\hline Simazina & Câncer de próstata, câncer de ovário (triazina), mal de Parkinson (Mostafalou \& Abdollahi, 2017). \\
\hline Sulfentrazona & Resíduos persistentes na água e em organismos. Não atende ao limite máximo de resíduo, 0,01 mg/Kg \\
& (European Comission, 2020b); genotóxico (Bianchi et al., 2015, 2016). \\
\hline Tebuconazol & Efeitos deletérios sobre células hepáticas (Knebel et al., 2018, 2019). \\
\hline Tebutiurom & $\begin{array}{l}\text { Resíduos persistentes na água e em organismos. Não atende ao limite máximo de resíduo, 0,01 mg/Kg } \\
\text { (European Comission, 2020b); bioacumula em peixes (Jonsson et al., 2019), desregulador endócrino em }\end{array}$ \\
peixes (Almeida et al., 2018). \\
\hline Tiametoxam & Efeitos deletérios sobre as abelhas (Domingues et al., 2017). \\
\hline Tiodicarbe & $\begin{array}{l}\text { Efeitos sobre rins, fígado, sistema imunológico, em baixas doses (Dias et al., 2013), efeitos neurotóxicos } \\
\text { sobre peixes (Yi et al., 2006). Na Unão Europeia, alerta para o risco decorrente do consumo de uvas e } \\
\text { vinho contaminados, bem como da água subterrânea, devido ao seu uso como moluscidida (European } \\
\text { Comission, 2020b). }\end{array}$ \\
\hline
\end{tabular}

Dentre os 611 novos agrotóxicos autorizados no Brasil entre janeiro de 2019 e junho de 2020 contendo ingredientes ativos químicos, $359(58,7 \%)$ são produtos técnicos. Dos 252 restantes, as culturas agrícolas que tiveram mais de 50 novos agrotóxicos aprovados para uso foram: soja (150 novos agrotóxicos químicos, $59,5 \%$ do total, excetuando-se os produtos técnicos); algodão (111, 44,0\%); milho (110, 43,7\%); cana-de-açúcar (97, 38,5\%); feijão (88, 34,9\%); citros (80, 31,7\%); café (80, 31,7\%); tomate $(78,31,02 \%)$; trigo $(70,27,8 \%)$; batata ( 64 , 25,4\%); $\operatorname{arroz}(61,24,2 \%)$ e maçã $(53,21,0 \%)$.

Desenvolvidas com a promessa de diminuir o uso de agrotóxicos por carregarem genes de resistência a herbicidas e/ou genes que produzem toxinas, com função inseticidas, as variedades transgênicas de soja, milho e algodão ocuparam $95,7 \%, 88,9 \%$ e $89,8 \%$, respectivamente, da área total cultivada no Brasil de cada uma destas espécies (Céleres, 2019). No entanto, houve um aumento significativo do uso de agrotóxicos, pois plantas invasoras se tornaram resistentes aos herbicidas e as pragas-alvo se tornaram também resistentes às toxinas produzidas pelas plantas transgênicas, o que exigiu aumento no uso de herbicidas e inseticidas. Além disso, são cultivadas em extensos monocultivos, sistema mais sensível à ocorrência de epidemias de pragas e doenças, do que sistemas orgânicos ou agroecológicos. Adicionalmente, o fato de as culturas de soja, milho, algodão e cana-de-açúcar constarem entre as que tiveram o maior número de novos agrotóxicos com uso autorizado no Brasil entre janeiro de 2019 e junho de 2020 não surpreende, uma vez que, conforme descrito por Bombardi (2017), 52\% dos agrotóxicos utilizados no Brasil são aplicados em plantações de soja; $10 \%$, milho; $10 \%$, cana-de-açúcar; e 7\%, algodão. Assim, $79 \%$ dos agrotóxicos utilizados no país são aplicados naquelas quatro culturas agrícolas. É relevante destacar, ainda, que mais de $80 \%$ daqueles produtos agrícolas não são destinados à alimentação humana, mas, sim, à alimentação animal ou à produção de 
commodities, que juntamente com café, maçã e citros constituem a base do agronegócio brasileiro.

"A grande relevância do mercado brasileiro" de agrotóxicos "pode ser explicada pela extensão da área plantada no País, que em 2012 correspondia a $5 \%$ da área plantada mundial", conforme consta no Relatório 3 - Defensivos agrícolas, publicação da Bain \& Company (2014,p. 6), um estudo financiado pelo BNDES sobre o Potencial da Diversificação da Indústria Química Brasileira. Segundo o mesmo relatório, o volume de agrotóxicos comercializados no Brasil chegava a aproximadamente $20 \%$ do total mundial. A proporção de quatro vezes mais agrotóxicos por área cultivada no Brasil, comparativamente ao mundo, não foi elucidada no documento, contudo, o referido relatório mencionou que os volumes de agrotóxicos utilizados por área plantada nas culturas de soja e de cana-de-açúcar eram de 2 e 3 vezes maiores do que a média global, respectivamente (Bain \& Company, 2014).

\section{Os efeitos perversos da deriva para a vizinhança, consumidores e o meio ambiente}

Além dos efeitos adversos comprovados na saúde humana ou animal, o aumento da oferta e do uso de agrotóxicos também agrava sua ação lesiva sobre atividades agrícolas de terceiros. Exemplo disso é o efeito em cultivos agrícolas distantes do ponto de aplicação do pesticida, a centenas de metros ou mesmo de alguns quilômetros. No caso dos herbicidas, a comprovação da propriedade de deriva a distâncias longevas vem sendo feita desde a década de 1980. Especificamente, o 2,4-D alcançou $60 \%$ dos ingredientes ativos de herbicidas que foram detectados no ar em estudo feito pelo U.S Geology Survey nos anos 1990 nos Estados Unidos (Majewski \& Capel, 1995).

No Brasil, herbicidas à base de 2,4-D também têm sido utilizados, de forma crescente, em pulverização sobre plantas de variedades transgênicas de soja e milho resistentes ao referido herbicida. Provocado pelos efeitos adversos causados por esse sistema produtivo, o Ministério Público Federal ajuizou em 2014 Ação Civil Pública (ACP) que visava a tutelar a saúde pública e o meio ambiente, assim como coibir os efeitos danosos pelo uso do 2,4-D². Com base em manifestação preliminar conjunta do MAPA e da Comissão Técnica Nacional de Biossegurança (CTNBio) "apontando os efeitos deletérios do deferimento da ordem liminar, em especial o impacto negativo na agricultura nacional que perderia em eficiência, gerando risco de desabastecimento e impactando diretamente a balança comercial brasileira", a Procuradoria Regional da União da $1^{a}$ Região se manifestou na referida ACP argumentando que "o elemento questionado $(2,4-\mathrm{D})$ está em uso no mercado há mais de 60 anos, sem notícias de acidentes com o mesmo, bem como que a substância é de uso seguro sendo utilizada em diversos países do mundo" (ACP n ${ }^{\circ} 21372-$ 34.2014.4.01.3400).

$O$ juiz federal indeferiu o pedido de antecipação de tutela com base no argumento de que não há nada de indicativo de que o elemento 2,4-D deva ter o seu uso imediatamente proibido no Brasil. O tempo se encarregou de demonstrar que MAPA,

${ }^{2} \mathrm{ACPn}^{\circ}$ 21372-34.2014.4.01.3400. Disponível em: <https://www.jusbrasil.com.br/processos/221207691/processo-n-0021372-3420144013400-do$-\operatorname{trf}-1>$ 
CTNBio, Procuradoria Geral da União e o juiz que julgou a ação, se equivocaram em suas decisões. Cinco anos depois, com o avanço do cultivo de variedades transgênicas para as áreas cultivadas com outras espécies, agricultores e técnicos constataram no Rio Grande do Sul o aparecimento de fitoxidade em plantas sobre as quais herbicidas não eram aplicados. Os laudos das análises de resíduos em 143 amostras coletadas em 2019, de tomate, ameixa, couve, videira, oliveira, noz-pecã, maçã, caqui, pastagens e cinamomo no Rio Grande do Sul, realizadas pelo Laboratório de Análises de Resíduos de Pesticidas (Larp), vinculado à Secretaria da Agricultura, Pecuária e Desenvolvimento Rural do Estado do Rio Grande do Sul - SEAPDR, indicaram a presença do herbicida 2,4-D em 92,3\% delas (G1-RS, 2019). Ato contínuo, o governo publicou no Diário Oficial do Estado do Rio Grande do Sul, em 04/12/2019, a Instrução Normativa $N^{\circ} 15$ da SEAPDR, a qual suspendeu até o dia 31/12/2019, em todo o território estadual, o uso e a aplicação dos herbicidas a base de 2,4-D.

Resultados similares de cultivos de terceiros contaminados foram obtidos em meados de 2020 . Resíduos de 2,4-D foram detectados em 87,13\% das 171 amostras coletadas em 54 municípios do Rio Grande do Sul. A SEAPDR, em parceria com Ministério Público Estadual (MPE), por meio da Promotoria do Meio Ambiente, decidiu instalar estações meteorológicas que vão monitorar a deriva do 2,4-D (SEAPDR, 2020).

Nos estudos sobre pulverizações aéreas, em geral a deriva tem sido maior comparativamente às aplicações por equipamentos acoplados em tratores ou pulverizadores costais. Embora haja evidências científicas de que existe uma grande variação da quantidade do produto comercial que faz parte da deriva, um estudo mostrou que $47 \%$ do volume utilizado na pulverização por uma aeronave não atingiu o alvo (Pessoa \& Chaim, 1999). Assim, nas regiões onde a topografia não dificulta o uso de aeronaves e a escala de um cultivo (como lavouras de variedades de soja transgênica na região na Campanha do RS), o uso de aeronaves para efetuar pulverizações já é substancial, o que tem contribuído para o aumento da deriva dos produtos químicos pulverizados. Quanto maior a deriva, maior o dano direto a ser causado na vizinhança, até onde o vento e a chuva alcançam.

A deriva dos agrotóxicos, além de bem documentada na literatura científica, tem sido verificada a partir episódios frequentes de contaminação em diversas localidades do território nacional. Por exemplo, plantios de videira no Rio Grande Sul, na safra de 2018/2019, foram afetados pela toxicidade de herbicidas à base de 2,4-D utilizados em propriedades de terceiros, distantes dos locais de aplicação destes produtos (Carta Campinas, 2019). Anteriormente, Pignati et al. (2007) relataram que em março de 2006, dois dias depois que as nuvens ou 'chuvas' de agrotóxicos oriundos de pulverizações por aeronaves alcançaram a cidade de Lucas do Rio Verde (MT), ocorreu a queima ou secamento de plantas da maioria das 65 chácaras de hortaliças e legumes (localizadas em vários bairros da cidade). Os autores verificaram ainda o processo de secagem da maioria das folhas das plantas do Horto de Plantas Medicinais (localizado no centro da cidade), no qual eram mantidas diferentes espécies de plantas medicinais em 180 canteiros. Por fim, os autores constataram a queima de milhares de plantas ornamentais das ruas e quintais da periferia e do centro de Lucas do Rio Verde. As pulverizações aéreas também aumentam as situações de riscos à 
saúde humana. O estudo de Pignati et al. (2007), denominado de "acidente rural ampliado", mostra que as ações de vigilância do "uso e abuso" de agrotóxicos ampliaram-se para "movimento pelo desenvolvimento sustentável da região", apoiado na vigilância participativa, articulada com a luta pela democracia e justiça social, na busca de uma agricultura e/ou ambiente sustentável.

Posteriormente, em maio de 2013, a pulverização de agrotóxico por meio de avião agrícola atingiu em cheio a Escola Municipal Rural São José do Pontal, localizada no Assentamento Pontal do Buriti, município de Rio Verde (Goiás), intoxicando pessoas e contaminando o ambiente escolar e da comunidade do entorno. Os detalhes dos fatos após o acidente previsível estão descritos por Oliveira (2014) e na Ação Civil Pública de 2013 n 0002437 59.2013.4.01.3503. Embora as informações da imprensa tenham sido desencontradas, das 115 pessoas que estavam na escola no momento em que a nuvem de agrotóxicos as atingiu, 35 apresentaram sintomas fortes de intoxicação e foram conduzidas ao Hospital Municipal da cidade de Montividiu (Goiás), com o apoio do SAMU (Oliveira, 2014). Como é comum ocorrer em casos dessa natureza, informa o referido artigo que "a empresa responsável pela pulverização se comunicou com a imprensa negando ter despejado agrotóxico sobre a escola" (Oliveira, 2014, p. 115). Pouco menos de dois meses após ter sido contaminada, a Escola Municipal Rural São José do Pontal sofreu nova violência: foi depredada. A documentação relacionada ao caso, acima referenciada, cita ainda as tentativas de silenciar os atingidos e o silenciamento da imprensa sobre a responsabilidade dos fatos ocorridos (Oliveira, 2014).

A consequência da ausência de rigor durante a tomada de decisão pelas agências regulatórias no processo de registro, a ausência de restrição de uso e o não reconhecimento e a morosidade pelo Poder Judiciário, sobre os efeitos danosos na sua plenitude, resulta que o uso dos agrotóxicos continua a causar danos que se materializam em humanos, animais e meio ambiente, como também em prejuízos sócioeconômicos aos agricultores (como a perda de safras e a morte de plantas, causados por terceiros, no caso de agrotóxicos que são trazidos pelo vento e pela chuva).

Sobre a regulamentação da aviação agrícola no país, em âmbito federal, estão em vigor o Decreto-Lei $n^{\circ}$ 917/1969, que foi posteriormente regulamentado pelo Decreto $n^{\circ} 86.765 / 1981$. Com o avanço dos estudos sobre intoxicações por agrotóxicos, bem como a deriva durante as pulverizações, agravadas pelo uso de aeronaves, comparativamente aos outros métodos, municípios tomaram a iniciativas de aprovar normas que proibiram ou restringiram a pulverização aérea. Da mesma forma, pelo menos em 15 Estados foram apresentados projetos de lei visando também a proibição da pulverização aérea. Assim, o Ceará se tornou o primeiro estado a aprovar uma lei a respeito da matéria. Segundo a Lei 16.820/2019, a qual em seu Art. $1^{\circ}$ altera a Lei Estadual $n^{\circ} 12.228 / 1993$ estabelecendo que "é vedada a pulverização área de agrotóxicos na agricultura no Estado do Ceará" (Ceará, 2019).

O Partido Social Liberal (PSL) moveu Ação Direta de Inconstitucionalidade (ADI) contra a Lei Estadual $n^{\circ}$ 16.820/2019 (ADI n ${ }^{\circ}$ 062971280.2019.8.06.0000), que foi declarada extinta pelo desembargador Francisco de Assis Filgueira Mendes, do Tribunal de Justiça do Ceará (TJCE). Ainda em 2019, a Confederação da Agricultura e Pecuária do Brasil - CNA também ajuizou outra Ação Direta de Inconstitucionalidade (ADI ${ }^{\circ} 6.137 / \mathrm{CE}$ ), agora 
no Supremo Tribunal Federal, solicitando que seja declarada a inconstitucionalidade da Lei Estadual $\mathrm{n}^{\mathrm{o}}$ 16.820/2019 do Estado do Ceará. Provocada, a Procuradoria Geral da República, por meio da $4^{\text {a }}$ Câmara de Coordenação e Revisão - CCR se manifestou contrária ao argumento de que a norma estadual representava "usurpação da competência privativa da União". A Nota da $4^{\mathrm{a}}$ CCR enfatiza ainda que "por tratar a lei estadual fundamentalmente de matéria ambiental, aplica-se a este caso a competência da união, estados e Distrito Federal para legislar concorrentemente sobre proteção do meio ambiente e controle da poluição". Outro argumento apresentado pela PGR igualmente contrário à pretensão da CNA, de que, em matéria de agrotóxicos, vigora, em âmbito federal, a Lei 7.802/1989, que no Artigo 10 estabelece que "Compete aos Estados e ao Distrito Federal, nos termos dos artigos 23 e 24 da Constituição Federal, legislar sobre o uso, a produção, o consumo, o comércio e o armazenamento dos agrotóxicos, seus componentes e afins, bem como fiscalizar o uso, o consumo, o comércio, o armazenamento e o transporte interno" (MPF-PGR, 2019). Contudo, até o momento da publicação deste artigo, a referida ADI ainda não foi julgada.

\section{O papel da ciência na avaliação dos impactos de agrotóxicos}

Desde 2008, o Brasil é o maior importador de agrotóxicos de toda a América Latina. Este fato provavelmente ocorre porque não existe no país uma política que obrigue as agências governamentais ao constante monitoramento do uso de tais substâncias, nem do efeito dos seus resíduos na água, nos alimentos e no meio ambiente. Não existem dados que contribuam para a manutenção de um inventário contemplando os efeitos de contaminantes em organismos não alvos. A ausência de monitoramento e fiscalização impede que os avanços científicos, citados na Tabela 3, sejam correlacionados com a diminuição de animais de várias espécies terrestres e de água doce. Além disso, as normas legais e políticas públicas poderiam ser mais abrangentes e mandatórias em termos de diagnósticos de doenças e a possível associação com os dados da Tabela 3 . Contudo, os únicos parâmetros avaliados dizem respeito à potabilidade da água e às suas características físico-químicas.

$\mathrm{O}$ setor produtivo também contribui para o aumento no uso de agrotóxicos. A ampla aplicação de agrotóxicos, os riscos desconhecidos, a não utilização (ou utilização incorreta) de equipamentos de proteção individual, as violações das legislações vigentes e o agravamento dos problemas sociais também contribuem para o aumento no número de intoxicações e contaminação ambiental no País (Bassani et al., 2018).

Conforme o cenário já apresentado acima, é inevitável que diversos compostos químicos potencialmente perigosos acabem se dispersando e contaminando o ambiente (Tabela 3). Assim, é de extrema importância que seja feito um monitoramento constante, tanto da presença quanto dos efeitos nocivos nos diferentes tipos de organismos não alvos.

Conforme levantamento de Lopes \& Albuquerque (2018), as publicações científicas sobre os impactos ambientais do uso de agrotóxicos realizadas entre 2011 e 2017 evidenciam os prejuízos causados sobre os insetos, as águas, os solos e os peixes pelo uso dessas substâncias, muitas vezes por alterarem seus habitats naturais. Isso demonstra que 
a aplicação desses compostos não se restringe às lavouras, estendendo-se aos mais diversos compartimentos ambientais. Quando se trata de pulverização aérea, essas consequências podem ser ainda mais drásticas. Todos os brasileiros deveriam ser alertados para o fato de que os agrotóxicos aplicados em um determinado lugar podem se deslocar para outros - junto com os alimentos, com a água das chuvas ou com o vento. Neste contexto, os agentes de saúde, os extensionistas rurais, os pesquisadores e os professores, dentre outros, podem assumir um papel determinante em processos de tomada de consciência mais amplos e vigorosos sobre os riscos atuais e potenciais envolvidos na utilização desses produtos.

Além disso, diversos tipos de biomarcadores poderiam auxiliar na criação de estratégias de monitoramento e fiscalização de impactos dos agrotóxicos. Neste sentido, caberia às universidades e centros de pesquisa assumirem um papel mais proativo no desenvolvimento de modelos experimentais em animais baseados nesta técnica. Esses biomarcadores podem ser usados para vários propósitos, dependendo da finalidade do estudo e do tipo da exposição, e podem ser classificados em três tipos: de exposição, de efeito e de suscetibilidade, os quais são instrumentos que possibilitam identificar a substância tóxica ou uma condição adversa, antes que sejam evidenciados danos à saúde (Amorim, 2003).

Nas últimas décadas, aumentou a demanda pela implementação de testes e critérios que categorizem os efeitos tóxicos dos compostos aplicados. $\mathrm{O}$ número de evidências sobre os efeitos dos agrotóxicos na saúde humana, organismos não alvo e meio ambiente em geral tem aumentado extensivamente. Em função das comprovações científicas dos danos causados pelos pesticidas, a União Europeia estabeleceu como meta diminuir pela metade o uso destes até 2030 , e assegurar que pelo menos $25 \%$ das terras utilizadas para agricultura sejam reservadas para cultivo orgânico. Atualmente, a proporção da área de cultivo com orgânicos é menor do que $10 \%$ na União Europeia (European Comission, 2020a).

A investigação acerca da exposição aos agrotóxicos constitui um importante aspecto para a saúde pública. Por isso, os estudos científicos que buscam investigar os riscos potenciais dos agrotóxicos e gerar dados sobre os impactos à saúde humana geralmente são baseados em análises feitas a partir de estudos usando modelos animais, justamente devido à similaridade genética, fisiológica, patológica, farmacológica e comportamental (Andersen \& Winter, 2019). Esses levantamentos sobre os níveis seguros de exposição permitem estabelecer os limites de exposição a uma substância isoladamente, conforme mostrado na Tabela 3. Porém, essas inferências não consideram a exposição conjunta e crônica a que a população é continuamente submetida. As investigações acerca da exposição a múltiplos agrotóxicos, que atualmente tornaram-se mais comuns (devido à diversidade de produtos utilizados num único cultivo) constituem uma importante contribuição ao campo da saúde pública. Essas informações obtidas por meio de testes em animais podem ser combinadas com observações clínicas em indivíduos expostos em contextos ocupacionais, permitindo o estabelecimento de novas relações causais.

Uma contribuição relevante da ciência em relação à investigação da toxicidade dos agrotóxicos através de experimentos controlados, e que vai além da toxicidade, diz respeito à compreensão do modo de ação das substâncias químicas. Isso possibilita extrapolar os efeitos para diferentes organismos ou 
predizer danos que potencialmente sejam causados a outras espécies. De acordo com Pereira et al. (2014), os sinais de toxicidade aguda induzida por agrotóxicos organofosforados e agentes neurotóxicos em várias espécies animais - desde pequenos roedores, como camundongos, ratos e porquinhos da índia, a grandes mamíferos, incluindo primatas não humanos —, se assemelham aos apresentados por humanos expostos, justificando assim o uso desses modelos animais na reprodução dos efeitos tóxicos.

Dentre as pesquisas sobre a toxicidade de pesticidas realizadas no Brasil, concentradas nas regiões Sul, Sudeste e Centro-Oeste, o modelo experimental animal mais utilizado é o peixe. Nos últimos anos, aproximadamente um terço dos trabalhos de toxicidade de pesticidas utilizaram espécies de peixes em suas investigações. Os peixes ósseos (Osteichthyes) formam o grupo mais abundante dos vertebrados e são encontrados em praticamente todos os ecossistemas aquáticos (Froese \& Pauly, 2020). Outra vantagem é que os peixes apresentam respostas biológicas a agentes tóxicos semelhantes a grandes vertebrados (Al-Sabti \& Metcalfe, 1995) e respondem a produtos químicos em baixas concentrações. Além disso, absorvem os compostos testados por diferentes vias, como absorção direta pela pele e brânquias, ou pela água e alimentos.

Nesse contexto, o uso do "zebrafish" (Danio rerio) é uma plataforma biológica importante para testes de toxicidade de agrotóxicos, um modelo vertebrado integrativo ideal para estudos de toxicidade. Eles são 70\% similares geneticamente aos seres humanos, têm um ciclo de vida curto (fácil de acompanhar todos os estágios) e são transparentes (é possível ver o que acontece em todo o organismo do animal em tempo real). Em função dessa similaridade genética, os modelos de "zebrafish" são estabelecidos para estudar processos biológicos, incluindo o desenvolvimento e os mecanismos de doença para translação para a saúde humana.

Estudos que investigam as respostas a doses de agrotóxicos combinados (a exemplo de Sergievich et al., 2020) sugerem que efeitos negativos podem ocorrer mesmo em doses várias vezes inferiores àquelas estabelecidas pelo Nivel Sem Efeitos Adversos Observáveis (NOAEL). Pesquisas futuras precisam incorporar mais doses de sub-NOAEL para revelar se quantidades muito baixas induzem efeitos negativos relativamente à dose NOAEL. As comparações dos resultados associados a distintas doses com a ingestão diária aceitável (IDA) indicam que as IDA não são suficientemente baixas para proteger contra os efeitos da combinação de pesticidas verificados em ratos (Hass et al., 2012).

Uma reportagem publicada no jornal $O$ Estado de São Paulo divulgou dados de uma análise brasileira (Ferreira, 2019) que utilizou o "zebrafish" para avaliar a toxicidade de 10 importantes agrotóxicos usados no território nacional: abamectina, acefato, alfa-cipermetrina, bendiocarb, carbofurano, diazinon, etofenprox, glifosato, malation e piripoxifem. Foram testadas diferentes concentrações dos agrotóxicos, desde as doses mínimas indicadas (Dose Diária Ideal) até concentrações equivalentes a 1/30 dessas dosagens. Em seguida, em intervalos de 24, 48, 72 e 96 horas, os embriões foram analisados no microscópio para avaliar se a exposição havia causado deformidades e, também, se tinha inviabi-

\footnotetext{
${ }^{3}$ Jansen, R. Pesquisa indica que não há dose segura de agrotóxico. O Estado de São Paulo, 04 de agosto de 2019. Disponível em: <https:// sustentabilidade.estadao.com.br/noticias/geral,pesquisa-indica-que-nao-ha-dose-segura-de-agrotoxico,70002953956>
} 
lizado o desenvolvimento. Os resultados mostraram que três dos dez agrotóxicos analisados (glifosato, melation e piriproxifem) causaram a morte de todos os embriões de peixes em apenas 24 horas de exposição, independentemente da concentração do produto utilizada. Os outros sete pesticidas analisados (abamectina, acefato, alfa-cipermetrina, bendiocarb, carbofurano, diazinon e etofenprox) causaram mortes nos embriões em maior ou menor porcentagem, em diferentes concentrações testadas. E mesmo os que sobreviveram, apresentavam anomalias.

Assim, os resultados implicam que as avaliações de risco com base no critério NOAEL ou na IDA para agrotóxicos individuais estão sujeitas a subestimarem o risco. Neste contexto, há a necessidade de modificação dos procedimentos de avaliação de risco para agrotóxicos, a fim de levar em consideração os efeitos da mistura e o impacto potencialmente danoso da exposição sobre desenvolvimento e reprodução, em particular de animais.

Recentemente, Gonçalves et al. (2020) relataram o grande número de publicações que contribuíram para a demonstração da toxicidade dos agrotóxicos.

A ciência tem potencial para orientar mudanças políticas, e existe uma grande demanda por melhorias, quando se trata de agrotóxicos, seja no rastreamento mais cauteloso dos seus efeitos, seja no uso mais criterioso, reduzindo seus impactos negativos e encontrando alternativas. Progressivamente, os cientistas estão avançando na compreensão precisa dos efeitos dos produtos químicos agora em nosso arsenal, incluindo as diversas maneiras pelas quais eles são degradados no meio ambiente e os danos que causam à vida selvagem. Enquanto isso, estudos de coorte ao redor do mundo estão começando a fornecer resultados e mapear seus efeitos sobre o desenvolvimento das populações (Enserink et al., 2013).

Neste contexto, o aumento de rigor científico e a participação pública nos processos de tomada de decisão, entre outros, podem contribuir decisivamente para o cumprimento do parágrafo $6^{\circ}$ do Artigo $3^{\circ}$ da Lei 7.802/1989, que pró́be o registro de agrotóxicos no Brasil que revelarem características teratogênicas, carcinogênicas ou mutagênicas, que provoquem distúrbios hormonais ou causem danos ao meio ambiente, entre outros. Desta forma, há que se exigir maior robustez científica dos estudos aportados pelos proponentes das tecnologias, tais como estudos de alimentação de animais de longa duração (maior do seis meses); estudos intergeracionais; estudos de longa duração de doses subletais em componentes das biodiversidade, particularmente os polinizadores, entre outros, e criação de um fundo para financiar pesquisas sobre os possíveis efeitos adversos dos agrotóxicos na saúde humana e no meio ambiente a serem realizados por cientistas independentes. Da mesma forma, é necessário alterar as normas visando garantir a transparência e o acesso às informações processuais, parte delas atualmente sigilosas, para que ocorra a participação pública nos procedimentos de análise e de tomada de decisão dos pedidos de registros e autorização de agrotóxicos.

\section{Considerações finais}

O conteúdo do presente artigo demonstra, de forma robusta, que as normas brasileiras relativas aos agrotóxicos são muito permissivas, e a gestão (interpretação e operacionalização) das normas nos últimos anos aumentaram o potencial 
de envenenamento do país. De um lado, o elevado consumo, que cresceu mais de $40 \%$ de 2010 a 2018 - representando mais do que o dobro em aumento em comparação ao aumento da área cultivada no país. De outro lado, no período de janeiro de 2019 a julho de 2020, do total de produtos registrados, $40 \%$ continham ingredientes ativos que não tinham uso permitido na União Europeia (UE). A razão da proibição do uso na UE dos produtos autorizados no Brasil, no período referido, está associada aos efeitos adversos a humanos e a outros organismos resultantes da exposição aos ingredientes químicos de agrotóxicos, já descritos na literatura científica e sumarizados no presente artigo.

Ao mesmo tempo, a quantidade e a qualidade de estudos independentes demonstram que os efeitos dos agrotóxicos na saúde humana e no meio ambiente são muito mais significativos do que aqueles inicialmente previstos ou até inexistentes no ato do registro. Assim, há a necessidade de alteração das normas e procedimentos, no sentido de aumentar o rigor e a robustez cientifica dos estudos, para que a tomada de decisão seja de fato embasada cientificamente.

Os novos registros de uso de 2019 e 2020 foram principalmente para soja, milho, algodão e cana-de-açúcar, que são os pilares do agronegócio brasileiro. O cultivo de variedades destas quatro espécies, além de estar associado ao grande consumo de agrotóxicos, também está associado aos nefastos casos de intoxicação de pessoas e mortalidade de plantas em áreas de terceiros. A deriva de produtos aplicados sobre variedades transgênicas, em particular de herbicidas como o 2,4-D, tem causado danos a plantios de outras espécies, como a videira, mesmo distantes a centenas de metros dos locais de aplicação. A escalada da pulverização aérea se constitui também em escalada da deriva, devido ao fato de que este tipo de aplicação de agrotóxico aumenta drasticamente a deriva de todos os produtos pulverizados.

O fato do agrotóxico ser aplicado em um lugar e causar danos a terceiros próximos ou muito distantes indica a necessidade inadiável de incluir a participação pública nos processos de tomada de decisão. Para isso, a norma legal deve ser alterada para garantir o acesso à informação e a participação de representantes da sociedade no processo de registro e de autorização de agrotóxicos.

Outra fragilidade da norma brasileira refere-se ao estabelecimento de um valor de dose, abaixo da qual um dado agrotóxico seria seguro. Contudo, resultados experimentais de estudos mostraram que, por exemplo, os agrotóxicos à base de glifosato, melation e piriproxifem causaram a morte de embriões de peixes em apenas 24 horas de exposição, independentemente da concentração utilizada. Esta e outras evidências apoiam a hipótese de que simplesmente não existe dose segura para a exposição a tais produtos. Os avanços obtidos pela investigação científica de vanguarda justificam, assim, a adoção de providências urgentes visando questionar a pertinência e a legitimidade das normas instituídas em nosso País relativamente a este tópico.

\section{Referências}

Abass, K.; Turpeinen, M.; Pelkonen, O. An evaluation of the cytochrome $\mathrm{P} 450$ inhibition potential of selected pesticides in human hepatic microsomes. Journal of Environmental Science and Health, Part B, 44 (6), 53-563, 2009. doi: 10.1080/03601230902997766

Abouelghar, G. E.; El-Bermawy, Z. A.; Salman, H. M. S. Oxidative stress, hematological and biochemical alterations 
induced by sub-acute exposure to fipronil $\left(\mathrm{COACH}_{\mathbb{R}}\right)$ in albino mice and ameliorative effect of selenium plus vitamin E. Environmental Science and Pollution Research, 27, 78867900, 2020. doi: 10.1007/s11356-019-06579-9

Al-Sabti, K.; Metcalfe, C. D. Fish micronuclei for assessing genotoxicity in water. Mutation Research, 43 (2-3),121-135, 1995. doi: 10.1016/0165-1218(95)90078-0

Amorim, L. C. A. Os biomarcadores e sua aplicação na avaliação da exposição aos agentes químicos ambientais. Revista Brasileira de Epidemiologia, 6 (2), 158-170, 2003. doi: 0.1590/S1415-790X2003000200009

Andersen, M. L.; Winter, L. M. F. Animal models in biological and biomedical research - experimental and ethical concerns. Anais da Academia Brasileira de Ciências, 91 (supl. 1), 2019. doi: 10.1590/0001-3765201720170238

ANVISA - Agência Nacional de Vigilância Sanitária. Regularização de produtos agrotóxicos. Monografias autorizadas. 2020. Disponível em: <http://portal.anvisa. gov.br/registros-e-autorizacoes/agrotoxicos/produtos/monografia-de-agrotoxicos/autorizadas $>$. Acesso em: jul. 2020.

Almeida, M. D.; Pereira, T. S. B.; Batlouni, S. R.; Boscolo, C. N. P.; Almeida, E. A. Estrogenic and anti-androgenic effects of the herbicide tebuthiuron in male Nile tilapia (Oreochromis niloticus). Aquatic Toxicology, 194, 86-93, 2018. doi: 10.1016/j.aquatox.2017.11.006

Baek, B. H.; Kim, S. K.; Yoon, W.; Heo, T. W.; Lee, Y. Y.; Kang, H. K. Chlorfenapyr-induced toxic leukoencephalopathy with radiologic reversibility: a case report and literature review. Korean Journal of Radiology, 17 (2), 277-280, 2016. doi: 10.3348/kjr.2016.17.2.277

Bain \& Company. Potencial de diversificação da indústria química brasileira: relatório 3 - defensivos agrícolas. Rio de Janeiro: BNDES, 2014, 47 p. Disponível em: <https://www. bndes.gov.br/wps/wcm/connect/site/a056bf33-7b92-44c8-ace1-8a7ca65d8286/6_chamada_publica_FEPprospec0311_Defensivos.pdf?MOD=AJPERES\&CVID $=1$ z-GKwI\&CVID=1z-GKwI\&CVID=1z-GKwI\&CVID=$\begin{array}{llllllllllllll} & \mathrm{G} & \mathrm{K} & \mathrm{W} & \mathrm{I} & \& & \mathrm{C} & \mathrm{V} & \mathrm{I} & \mathrm{D} & = & & 1 & -\end{array}$ z-GKwI\&CVID=lz-GKwI\&CVID=lz-GKwI\&CVID=lz$-\mathrm{GKwI} \& C V I D=\mathrm{z}-\mathrm{GK} w I \& C V I D=\mathrm{lz}-\mathrm{GKwI}>$. Acesso em: jul. 2020.
Bassani, D.; Silva, L. R.; Birk, L.; Franco de Oliveira, S. C. W. S. E.; Dallegrave, E.; Oliveira, T. F. Pesticides in Brazil: a viewpoint about the poison law. Journal of Agricultural and Food Chemistry, 66 (46),12153-12154, 2018. doi:10.1021/ acs.jafc. 8 b05669

Bianchi, J.; Cabral-de-Mello, D. C.; Marin-Morales, M. A. Toxicogenetic effects of low concentrations of the pesticides imidacloprid and sulfentrazone individually and in combination in in vitro tests with HepG2 cells and Salmonella typhimurium. Ecotoxicology and Environmental Safety, 120, 174-183, 2015. doi: 10.1016/j.ecoenv.2015.05.040

Bianchi, J.; Fernandes, T. C.; Marin-Morales, M. A. Induction of mitotic and chromosomal abnormalities on Allium cepa cells by pesticides imidacloprid and sulfentrazone and the mixture of them. Chemosphere, 144, 475-483, 2016. doi: 10.1016/j.chemosphere.2015.09.021

Bombardi, L. M. Geografia do uso de agrotóxicos no Brasil e conexões com a União Europeia. São Paulo: FFLCH-USP, 2017. Disponível em: <http://conexaoagua.mpf.mp.br/ arquivos/agrotoxicos/05-larissa-bombardi-atlas-agrotoxico-2017.pdf $>$. Acesso em: jul. 2020.

Brasil. Ministério da Agricultura, Pecuária e Abastecimento. Secretaria de Defesa Agropecuária. Departamento de Sanidade Vegetal e Insumos Agrícolas. Coordenação Geral de Agrotóxicos e Afins. Atos: 01 de 09/01/2019; 04 de 17/01/2019; 07 de 04/02/2019; 10 de18/02/2019; 17 de 19/03/2019; 24 de 09/04/2019; 29 de 29/04/2019; 34 de 16/05/2019; 42 de 19/06/2019; 48 de 19/06/2019; 62 de 13/09/2019; 70 de 02/10/2019; 82 de 25/11/2019; 91 de 26/12/2019; 12 de 19/02/2020; 13 de 19/02/2020; 22 de 25/03/2020; 26 de 04/04/2020; 28 de 22/04/2020; 31 de 04/05/2020; e 36 de 05/06/2020. Disponível em: <http:// www.in.gov.br/web/guest/inicio>. Acesso em: jul. 2020.

Brasil. Lei $N^{o} 7.802$, de 11 de julho de 1989. Disponível em: $<$ http://www.planalto.gov.br/ccivil_03/leis/17802.htm>. Acesso em: jul. 2020.

Brock, T. C. M.; Belgers, J. D. M.; Boerwinkel, M-C.; Jollie, L.; Kraak, M. H. S.; Papo, M. J.; Vonk, J. A.; Roessink, I. Toxicity of sediment-bound lufenuron to benthic arthropods in laboratory bioassays. Aquatic Toxicology, 198, 118-128, 2018. doi: 10.1016/j.aquatox.2018.03.005 
Carta Campinas. Agrotóxico usado na soja está destruindo a produção de vinho no Rio Grande do Sul. Publicado em 28/05/2019. Disponível em: <https://cartacampinas.com. br/2019/05/agrotoxico-usado-na-soja-esta-destruindo-a-producao-de-vinho-no-rio-grande-do-sul/>. Acesso em: ago. 2020.

Carvalho, M. M. X.; Nodari, E. S.; Nodari, R. O. "Defensives" or "pesticides"? A history of the use and perception of pesticides in the state of Santa Catarina, Brazil, 1950-2002. História, Ciências, Saúde-Manguinhos, 24(1), 75-91, 2017. doi: 10.1590/s0104-59702017000100002

Ceará. Lei 16.820, de 08 de janeiro de 2019. Dispõe sobre o uso, a produção, o consumo, o comércio e o armazenamento dos agrotóxicos, seus componentes e afins bem como a fiscalização do uso de consumo do comércio, do armazenamento e do transporte interno desses produtos. Fortaleza: Diário Oficial do Estado do Ceará, série 3, ano XI, Nº06, de 09 de janeiro de 2019.

Céleres. Adoção de biotecnologia 2018/19: análise geral. Informativo Biotecnologia IB19.01. 2019. Disponível em: $<$ http://www.celeres.com.br/wp-content/uploads/2019/11/ BoletimBiotecnologiaC\%C3\%A9leres_Novembro2019-2. pdf>. Acesso em: ago. 2020.

Dhanushka, M. A.; Peiris, L. D. Cytotoxic and genotoxic effects of acephate on human sperm. Journal of Toxicology, 2, 1-6, 2017. doi: 10.1155/2017/3874817

Dias, E.; Gomes, M.; Domingues, C.; Ramalheira E.; Morais, S.; Pereira, M. L. Subacute effects of the thiodicarb pesticide on target organs of male Wistar rats: biochemical, histological, and flow cytometry studies. Journal of Environmental Science and Health, Part A, 76 (9), 533-539, 2013. doi: $10.1080 / 15287394.2013 .785216$

Domingues, C. E. C.; Abdalla, F. C.; Balsamo, P. J.; Pereira, B. V. R.; Hausen, M. A.; Costa, M. J.; Silva-Zacarin, E. C. M. Thiamethoxam and picoxystrobin reduce the survival and overload the hepato-nephrocitic system of the Africanized honeybee. Chemosphere, 186, 994-1005, 2017. doi: 10.1016/j.chemosphere.2017.07.133

Emadi, M.; Maghami, P.; Khorsandi, K.; Hosseinzadeh, R. Biophysical study on the interaction of cartap hydrochloride and hemoglobin: heme degradation and functional changes of protein. Journal of Biochemical and Molecular Toxicology, 33 (7), e22325, 2019. doi: 10.1002/jbt.22325

Enserink, M.; Hines, P. J.; Vignieri, S. N.; Wigginton, N. S.; Yeston, J. S. The pesticide paradox. Science, 341 (6147), 728-729, 2013. doi: 10.1126/science.341.6147.728

European Comission. A farm to fork strategy for a fair, healthy and environmentally-friendly food system. Brussels, COM (2020) 381 final, 2020a. Disponível em: $<$ https://eur-lex.europa.eu/legal-content/EN/TXT/?qi$\mathrm{d}=1590404602495 \&$ uri=CELEX\%3A52020DC0381>. Acesso em: jul. 2020.

European Comission. Plants - EU pesticides database. 2020b. Disponível em: <http://ec.europa.eu/food/plant/ pesticides/eu-pesticides-database/public/?event=activesubstance.selection\&language $=\mathrm{EN}>$. Acesso em: jul. 2020 .

Faita, M. R.; Oliveira, E. M.; Alves Júnior, V. V.; Orth, A. I.; Nodari, R. O. Changes in hypopharyngeal glands of nurse bees (Apis mellifera) induced by pollen-containing sublethal doses of the herbicide Roundup. Chemosphere, 211, 566572, 2018. doi: 10.1016/j.chemosphere.2018.07.189.

Faita, M. R.; Cardozo, M. M.; Amandio, D. T. T.; Orth, A. I.; Nodari, R. O. Glyphosate-based herbicides and Nosema sp. microsporidia reduce honey bee (Apis mellifera L.) survivability under laboratory conditions. Journal of Apicultural Research, 59 (4), 332-342, 2020. doi: 10.1080/00218839.2020.1736782

Ferreira, M. V. A. L. Mortes e anomalias causadas por agrotóxicos revelam a fragilidade das "doses seguras" nos alimentos e na água. Apresentação na audiência pública do Fórum Catarinense de Combate aos Impactos dos Agrotóxicos e Transgênicos - FCCIAT, em 23 de outubro de 2019. Disponível em: $<$ https://fcciat.blogspot.com/2019/10/ mortes-e-anomalias-causadas-por.html? spref $=\mathrm{fb} \& \mathrm{~m}=1>$. Acesso em: nov. 2020.

Froese, R.; Pauly, D. FishBase - World Wide Web Electronic Publication. Disponível em: <www.fishbase.org $>$. Acesso em: ago. 2020.

G1-RS. Uso do herbicida 2,4-D é suspenso até o fim do ano pela Secretaria da Agricultura do RS. G1-RS, 03 de dezembro de 2019. Disponível em: <https://g1.globo.com/ rs/rio-grande-do-sul/noticia/2019/12/03/uso-do-herbicida- 
-24-d-e-suspenso-ate-o-fim-do-ano-pela-secretaria-da-agricultura-do-rs.ghtml>. Acesso em: jul. 2020.

Gammon, D. W.; Liu, Z.; Chandrasekaran, A.; El-Naggar, S. F.; Kuryshev, Y. A.; Jackson, S. Pyrethroid neurotoxicity studies with bifenthrin indicate a mixed Type I/II mode of action. Pest Management Science, 75 (4), 1190-1197, 2019. doi: $10.1002 /$ ps.5300

Golombieski, J. I.; Sutili, F. J.; Salbego, J.; Seben, D.; Gressler, L. T.; Cunha, J. A.; Gressler, L. T.; Zanella, R.; Vaucher, R. A.; Marchesan, E.; Baldisserotto, B. Imazapyr+imazapic herbicide determines acute toxicity in silver catfish Rhamdia quelen. Ecotoxicology and Environmental Safety, 128, 9199, 2016. doi: 10.1016/j.ecoenv.2016.02.010

Gonçalves, I. F. S.; Souza, T. M.; Vieira, L. R.; Marchi, F. C.; Nascimento, A. P.; Farias, D. F. Toxicity testing of pesticides in zebrafish - a systematic review on chemicals and associated toxicological endpoints. Environmental Science and Pollution Research, 27 (10), 10185-10204, 2020. doi: 10.1007/s11356-020-07902-5

Gutta, S.; Prasad, J. D.; Gunasekaran, K.; Iyadurai, R. Hepatotoxicity and neurotoxicity of fipronil poisoning in human: a case report. Journal of Family Medicine and Primary Care, 8 (10), 3437-3439, 2019. doi: 10.4103/ jfmpc.jfmpc_486_19

Hao, Y.; Zhang, H.; Zhang, P.; Yu, S.; Ma, D.; Li, L.; Feng, Y.; Min, L.; Shen, W.; Zhao, Y. Chlorothalonil inhibits mouse ovarian development through endocrine disruption. Toxicology Letters, 303, 38-47, 2019. doi: 10.1016/j. toxlet.2018.12.011

Hass, U.; Boberg, J.; Christiansen, S.; Jacobsen, P. R.; Vinggaard, A. M.; Taxvig, C.; Poulsen, M. E.; Herrmann, S.S.; Jensen, B. H.; Petersen, A.; Clemmensen, L. H.; Axelstad, $M$. Adverse effects on sexual development in rat offspring after low dose exposure to a mixture of endocrine disrupting pesticides. Reproductive Toxicology, 34(2), 261-274, 2012. doi: 10.1016/j.reprotox.2012.05.090.

Hess, S.C. Águas mal tratadas. In: Hess, S.C. (org.) Ensaios sobre poluição e doenças no Brasil, São Paulo: Outras Expressões, 2018, p.23-29.

Hess, S. C.; Nodari, R. O. Glifosato, o maior dos venenos. In: Hess, S. C. (Org.). Ensaios sobre poluição e doenças no Brasil. São Paulo: Outras Expressões, 2018, p. 151-164.

Hu, H.; Zhou, H.; Zhou, S.; Li, Z.; Wei, C.; Yu, Y.; Hay, A. G. Fomesafen impacts bacterial communities and enzyme activities in the rhizosphere. Environmental Pollution, 253, 302-311, 2019. doi: 10.1016/j.envpol.2019.07.018

IBGE - Instituto Brasileiro de Geografia e Estatística. SIDRA - Sistema IBGE de Recuperação Automática. Produção agricola municipal. Área plantada (hectares). Lavouras temporárias. Disponível em: <https://sidra.ibge.gov.br/ tabela/1612>. Acesso em: jul. 2020.

IBGE - Instituto Brasileiro de Geografia e Estatística. SIDRA - Sistema IBGE de Recuperação Automática. Produção agricola municipal. Area plantada (hectares). Lavouras permanentes. Disponível em: <https://sidra.ibge.gov.br/ tabela/1613>. Acesso em: jul. 2020.

IBAMA - Instituto Brasileiro do Meio Ambiente. Relatórios de comercialização de agrotóxicos. Disponível em: $<\mathrm{http}: / /$ www.ibama.gov.br/agrotoxicos/relatorios-de-comercializacao-de-agrotoxicos\#boletinsanuais $>$. Acesso em: jul. 2020.

Jonsson, C. M.; Moura, M. A. M.; Ferracini, V. L.; Paraíba, L. C.; Assalin, M. R.; Queiroz, S. C. N. Bioconcentrations of herbicides used in sugarcane crops in tilapia (Oreochromis niloticus) and the risk for human consumption. Heliyon, 5 (8), e02237, 2019. doi: 10.1016/j.heliyon.2019.e02237

Kalyaniwala, K.; Abhilash, K. Victor, P. J. Cartap hydrochloride poisoning. Journal of the Association of Physicians of India, 64 (8), 91-92, 2016. Disponível em: <https://pubmed. ncbi.nlm.nih.gov/27762121/ >. Acesso em: jul. 2020.

Knebel, C.; Buhrke, T.; Süssmuth, R.; Lampen, A.; Marx-Stoelting, P.; Braeuning, A. Pregnane X receptor mediates steatotic effects of propiconazole and tebuconazole in human liver cell lines. Archives of Toxicology, 93 (5), 1311-1322, 2019. doi: 10.1007/s00204-019-02445-2

Knebel, C.; Neeb, J.; Zahn, E.; Schmidt, F.; Carazo, A.; Holas, O.; Pavek, P.; Puschel, G. P.; Zanger, U. M.; Sussmuth, R.; Lampen, A.; Marx-Stoelting, P; Braeuning, A. Unexpected effects of propiconazole, tebuconazole, and their mixture on the receptors CAR and PXR in human liver cells. Toxicological Sciences, 163 (1), 170-181, 2018. doi: 10.1093/toxsci/kfy026 
Kushwaha, M.; Verma, S.; Chatterjee S. PROFENOFOS, an acetylcholinesterase-inhibiting organophosphorus pesticide: a short review of its usage, toxicity, and biodegradation. Journal of Environmental Quality, 45 (5), 1478-1489, 2016. doi: 10.2134/jeq2016.03.0100

Li, H.; Cao, F.; Zhao, F.; Yang, Y.; Teng, M.; Wang, C.; Qiu, L. Developmental toxicity, oxidative stress and immunotoxicity induced by three strobilurins (pyraclostrobin, trifloxystrobin and picoxystrobin) in zebrafish embryos. Chemosphere, 207, 781-790, 2018. doi: 10.1016/j.chemosphere.2018.05.146

Lopes, C. V. A.; Albuquerque, G. S. C. Agrotóxicos e seus impactos na saúde humana e ambiental: uma revisão sistemática. Saúde Debate, 42 (117), 518-534, 2018. doi: 10.1590/0103-1104201811714

Magalhães, N.; Carvalho, F.; Dinis-Oliveira, R. J. Human and experimental toxicology of diquat poisoning: Toxicokinetics, mechanisms of toxicity, clinical features, and treatment. Human and Experimental Toxicology, 37 (11), 1131-1160, 2018. doi: 10.1177/0960327118765330

Majewski, M. S.; Capel, P.D. Pesticides in the atmosphere: distribution, trends, and governing factors. Sacramento, CA: U.S. Geological Survey, 1995. 207 p.

Ministério da Agricultura, Pecuária e Abastecimento. AGROFIT - Sistema de Agrotóxicos Fitossanitários. Disponível em: $<$ http://agrofit.agricultura.gov.br/agrofit_cons/ principal_agrofit_cons $>$. Acesso em: jul. 2020.

Mostafalou, S.; Abdollahi, M. Pesticides: an update of human exposure and toxicity. Archives of Toxicology, 91(2), 549-599, 2017. doi: 10.1007/s00204-016-1849-x

Moustafa, G. G.; Ibrahim, Z. S.; Ahmed, M. M.; Ghoneim, M. H.; Sakamoto, K. Q.; Ishizuka, M.; Fujita, S. Downregulation of male-specific cytochrome $\mathrm{P} 450$ by profenofos. Japanese Journal of Veterinary Research, 56 (2), 109118, 2008. Disponível em: <https://pubmed.ncbi.nlm.nih. gov/18828448/>. Acesso em: jul. 2020.

MPF-PGR. Ministério Público Federal. Procuradoria Geral da República. Nota técnica $4^{\mathrm{a}} \mathrm{CCR} / 2019$. Nota técnica sobre a constitucionalidade do projeto de lei 16.820/2019 que trata da proibição da pulverização aérea de agrotóxicos no estado do Ceará. Disponível em: <http://www.mpf.mp.br/ $\mathrm{pgr} /$ documentos/nota_tecnica_pulverizacao_agrotoxicos. pdf $>$. Acesso em: ago. 2020.

Nesnow, S.; Padgett, W. T.; Moore, T. Propiconazole induces alterations in the hepatic metabolome of mice: relevance to propiconazole-induced hepatocarcinogenesis. Toxicoligical Sciences, 120 (2), 297-309, 2011. doi: 10.1093/toxsci/kfr012

Nganchamung, T.; Robson, M. G.; Siriwong, W. Association between blood cholinesterase activity, organophosphate pesticide residues on hands, and health effects among chili farmers in Ubon Ratchathani Province, northeastern Thailand. Roczniki Państwowego Zakładu Higieny, 68 (2), 175-183, 2017. Disponível em: <https://pubmed.ncbi.nlm. nih.gov/28646835/>. Acesso em: jul. 2020.

Noshy, P. A.; Elhady, M. A.; Khalaf, A. A. A.; Kamel, M. M.; Hassanen, E. I. Ameliorative effect of carvacrol against propiconazole-induced neurobehavioral toxicity in rats. Neurotoxicology, 67, 141-149, 2018. doi: 10.1016/j. neuro.2018.05.005

Nowak, K.; Jabłońska, E.; Ratajczak-Wrona, W. Immunomodulatory effects of synthetic endocrine disrupting chemicals on the development and functions of human immune cells. Environment International, 125, 350-364, 2019. doi: 10.1016/j.envint.2019.01.078

Oliveira, L. C. Intoxicados e silenciados: contra o que se luta? Tempus, Actas de Saúde Coletiva, 8(2), 109-132, 2014. doi: 10.18569/tempus.v8i2.1515

Pereira, E. F. R.; Aracava, Y.; DeTolla, L. J.; Beecham, J.; Basinger, W.; Wakayama, E. J.; Albuquerque, E. X. Animal models that best reproduce the clinical manifestations of human intoxication with organophosphorus compounds. Journal of Pharmacology and Experimental Therapeutics, 350 (2), 313-321, 2014. doi: 10.1124/jpet.114.214932

Perveen, N.; Ahmad, M. Toxicity of some insecticides to the haemocytes of giant honeybee, Apis dorsata F. under laboratory conditions. Saudi Journal of Biological Sciences, 24 (5), 1016-1022, 2017. doi: 10.1016/j.sjbs.2016.12.011

Pessoa, M. C. P. Y.; Chaim, A. Programa computacional para estimativa de uniformidade de gotas de herbicidas aplicados por pulverização aérea. Pesquisa Agropecuária Brasileira, 34(1), 45-56. 1999. doi: 10.1590/S0100204X1999000100007 
Pignati, W. A.; Machado, J. M. H.; Cabral, J. F. Acidente rural ampliado: o caso das "chuvas" de agrotóxicos sobre a cidade de Lucas do Rio Verde - MT. Ciência \& Saúde Coletiva, 12(1):105-114, 2007. doi: 10.1590/S141381232007000100014

Rathish, D.; Agampodi, S.; Jayasumana, C. Acetylcholinesterase inhibitor insecticides related acute poisoning, availability and sales: trends during the post-insecticide-ban period of Anuradhapura, Sri Lanka. Environmental Health and Preventive Medicine, 23 (1), 27, 2018. doi: 10.1186/ s12199-018-0716-1

Riaz-Ul-Haq, M.; Javeed, R.; Iram, S.; Rasheed, M. A.; Amjad, M.; Iqbal, F. Effect of diafenthiuron exposure under short and long term experimental conditions on hematology, serum biochemical profile and elemental composition of a non-target organism, Labeo rohita. Environmental Toxicology and Pharmacology, 62, 40-45, 2018. doi: 10.1016/j. etap.2018.06.006

Ribeiro, T. A.; Prates, K. V.; Pavanello, A.; Malta, A.; Tófolo, L. P.; Martins, I. P.; Oliveira, J. C.; Miranda, R. A.; Gomes, R. M.; Vieira, E.; Silva, C. C.; Barella, F. L. F.; Francisco, F. A.; Alves, V. S.; Silveira, S. S.; Moreira, V. M.; Fabrício, G. S.; Palma-Rigo, K.; Sloboda, D. M.; Mathias, P. C. F. Acephate exposure during a perinatal life program to type 2 diabetes. Toxicology, 30 (372), 12-21, 2016. doi: 10.1016/j.tox.2016.10.010

Robatscher, P.; Eisenstecken, D.; Innerebner, G.; Roschatt, C.; Raifer, B.; Rohregger, H; Hafner, H.; Oberhuber, M. 3-Chloro-5-trifluoromethylpyridine-2-carboxylic acid, a metabolite of the fungicide fluopyram, causes growth disorder in Vitis vinifera. Journal of Agricultural and Food Chemistry, 67 (26), 7223-7231, 2019. doi: 10.1021/acs. jafc. 8 b05567

Santorum, M.; Costa, R. M.; Reis, G. H.; Santos, D. C. Novaluron impairs the silk gland and productive performance of silkworm Bombyx mori (Lepidoptera: Bombycidae) larvae. Chemosphere, 239, e124697, 2020. doi: 10.1016/j.chemosphere.2019.124697.

Santorum, M.; Brancalhão, R. M. C.; Guimarães, A. T. B.; Padovanic, R.; Tettamantid, G.; Santos, D. C. Negative impact of Novaluron on the nontarget insect Bombyx mori (Lepidoptera: Bombycidae). Environmental Pollution, 249,
82-90, 2019. doi: 10.1016/j.envpol.2019.02.095

SEAPDR - Secretaria da Agricultura, Pecuária e Desenvolvimento Rural do Estado do Rio Grande do Sul. Estações meteorológicas começam a ser instaladas no RS e vão monitorar deriva do 2,4 D. Publicado em 22/07/2020. Disponível em: $<$ https://www.agricultura.rs.gov.br/estacoes-meteorologicas-comecam-a-ser-instaladas-no-rs-e-vao-monitorar-deriva-do-2-4-d >. Acesso em: jul. 2020.

Sergievich, A. A.; Khoroshikh, P. P.; Artemenko, A. F.; Zakharenko, A. M.; Chaika, V. V.; Kodintsev, V. V.; et al. Behavioral impacts of a mixture of six pesticides on rats. Science of The Total Environment, 727: 138491, 2020. doi: 10.1016/j.scitotenv.2020.138491

Soares, P. R. L.; Andrade, A. L. C.; Santos, T. P.; Silva, S. C. B. L.; Silva, J. F.; Santos, A. R.; Souza, E. H. L. S.; Cunha, F. M.; Teixeira, V. W.; Cadena, M. R. S.; Sá, F. B.; Carvalho Júnior, L. B.; Cadena, P. G. Acute and chronic toxicity of the benzoylurea pesticide, lufenuron, in the fish, Colossoma macropomum. Chemosphere, 161, 412-421, 2016. doi: 10.1016/j.chemosphere.2016.07.033

Souders, C. L. 2nd; Xavier, P.; Perez-Rodriguez, V.; Ector, N.; Zhang, J. L.; Martyniuk, C. J. Sub-lethal effects of the triazole fungicide propiconazole on zebrafish (Danio rerio) development, oxidative respiration, and larval locomotor activity. Neurotoxicology and Teratology, 74, e106809, 2019. doi: 10.1016/j.ntt.2019.106809

Stacke, R. F.; Giamomelli, T.; Bronzatto, E. S.; Halberstadt, S. A.; Garlet, C. G.; Muraro, D. S.; Guedes, J. V. C.; Bernardi, O. Susceptibility of brazilian populations of Chrysodeixis includens (Lepidoptera: Noctuidae) to selected insecticides. Journal of Economic Entomology, 112 (3), 1378-1387, 2019. doi: $10.1093 /$ jee/toz031

Teng, M.; Zhao, F.; Zhou, Y.; Yan, S.; Tian, S.; Yan, J.; Meng, Z.; Bi, S.; Wang, C. Effect of propiconazole on the lipid metabolism of zebrafish embryos (Danio rerio). Journal of Agricultural and Food Chemistry, 67 (16), 4623-4631, 2019. doi: 10.1021/acs.jafc.9b00449

Tu, T-Y.; Hong, C-Y.; Sasado, T.; Kashiwada, S.; Chen, P-J. Early life exposure to a rodent carcinogen propiconazole fungicide induces oxidative stress and hepatocarcinogenesis in medaka fish. Aquatic Toxicology, 170, 52-61, 2016. doi: 
10.1016/j.aquatox.2015.11.014

Valadas, J.; Mocelin, R.; Sachett, A.; Marcon, M.; Zanette, R. A.; Dallegrave, E.; Herrmann, A. P.; Piato, A. Propiconazole induces abnormal behavior and oxidative stress in zebrafish. Environmental Science and Pollution Research, 26 (27), 27808-27815, 2019. doi: 10.1007/s11356-019$05977-3$

Von Ehrenstein, O. S.; Ling, C.; Cui, X.; Cockburn, M.; Park, A. S.; Yu, F.; Wu, J.; Ritz, B. Prenatal and infant exposure to ambient pesticides and autismo spectrum disorder in children: population based case-control study. The British Medical Journal, 364, 1962-1971, 2019. doi: 10.1136/ bmj.1962

Waldo, B. D.; Grabau, Z. J.; Mengistu, T. M.; Crow, W. T. Nematicide effects on non-target nematodes in bermudagrass. Journal of Nematology, 51, 1-12, 2019. doi: 10.21307/ jofnem-2019-009

Wang, C.; Henderson, G.; Gautam, B. K. Lufenuron suppresses the resistance of formosan subterranean termites (Isoptera: Rhinotermitidae) to entomopathogenic bacteria. Journal of Economic Entomology, 106 (4), 1812-1818, 2013. doi: 10.1603/EC13068

Williamson, S. M.; Willis, S. J.; Wright, G. A. Exposure to neonicotinoids influences the motor function of adult worker honeybees. Ecotoxicology, 23 (8), 1409-1418, 2014. doi: 10.1007/s10646-014-1283-X

Xia, M.; Huang, R.; Shi, Q.; Boyd, W. A.; Zhao, J.; Sun, N.; Rice, J. R.; Dunlap, P. E.; Hackstadt, A. J.; Bridge, M. F.; Smith, M. V.; Daí, S.; Zheng, W.; Chu, P-H.; Gerhold, D.; Witt, K. L.; De Vito, M.; Freedman, J. H.; Austin, C. P.; Houck, K. A.; Thomas, R. S.; Paules, R. S.; Tice, R. R.; Simeonov, A. Comprehensive analyses and prioritization of Tox $2110 \mathrm{~K}$ chemicals affecting mitochondrial function by in-depth mechanistic studies. Environmental Health Perspectives, 126 (7), e077010, 2018. doi: 10.1289/EHP2589
Xiang, D.; Chu, T.; Li, M.; Wang, Q.; Zhu, G. Effects of pyrethroid pesticide cis-bifenthrin on lipogenesis in hepatic cell line. Chemosphere, v. 201, p. 840-849, 2018. doi: 10.1016/j.chemosphere.2018.03.009

Xiong, G.; Deng, Y.; Li, J.; Cao, Z.; Liao, X.; Liu, Y.; Lu, H. Immunotoxicity and transcriptome analysis of zebrafish embryos in response to glufosinate-ammonium exposure. Chemosphere, 236, e124423, 2019. doi: 10.1016/j.chemosphere.2019.124423

Yi, M. Q.; Liu, H. X.; Shi, X. Y.; Liang, P.; Gao, X. W. Inhibitory effects of four carbamate insecticides on acetylcholinesterase of male and female Carassius auratus in vitro. Comparative Biochemistry and Physiology Part C: Pharmacology, Toxicology and Endocrinology, 143 (1), 113-116, 2006. doi: 10.1016/j.cbpc.2005.12.008

Zhang, J.; Zhang, J.; Liu, R.; Gan, J.; Liu, J.; Liu, W. Endocrine-disrupting effects of pesticides through interference with human glucocorticoid receptor. Environmental Science \& Technology, 50 (1), 435-443, 2016. doi: 10.1021/acs. est.5b03731

Zhang, L.; Diao, J.; Chen, L.; Wang, Z.; Zhang, W.; Li, Y.; Tian, Z.; Zhou, Z. Hepatotoxicity and reproductive disruption in male lizards (Eremias argus) exposed to glufosinate-ammonium contaminated soil. Environmental Pollution, 246, 190-197, 2019. doi: 10.1016/j.envpol.2018.12.004

Zhang, P.; Zhao, Y.; Zhang, H.; Liu, J.; Feng, Y.; Yin, S.; Cheng, S.; Sun, X.; Min, L.; Li, L.; Shen, W. Low dose chlorothalonil impairs mouse spermatogenesis through the intertwining of estrogen receptor pathways with histone and DNA methylation. Chemosphere, 230, 384-395, 2019. doi: 10.1016/j.chemosphere.2019.05.029

Zhang, Q.; Zhu, L.; Wang, J.; Xie, H.; Wang, J.; Han, Y.; Yang, J. Oxidative stress and lipid peroxidation in the earthworm Eisenia fetida induced by low doses of fomesafen. Environmental Science and Pollution Research, 20 (1), 201-218, 2013. doi: 10.1007/s11356-012-0962-5 